\title{
Game theory based real-time multi-objective flexible job shop scheduling considering environmental impact
}

Yingfeng Zhang, J in Wang and Yang Liu

The self-archived postprint version of this journal article is available at Linköping University Institutional Repository (DiVA):

http:// urn.kb.se/ resolve?urn=urn:nbn:se:liu:diva-142826

N.B.: When citing this work, cite the original publication.

Zhang, Y., Wang, J., Liu, Y., (2017), Game theory based real-time multi-objective flexible job shop scheduling considering environmental impact, J ournal of Cleaner Production, 167, 665-679.

https:// doi.org/ 10.1016/j.jclepro.2017.08.068

Original publication available at:

https:// doi.org/ 10.1016/j.jclepro.2017.08.068

Copyright: Elsevier

http:// www.elsevier.com/

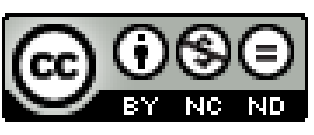




\section{Accepted Manuscript}

Game theory based real-time multi-objective flexible job shop scheduling considering environmental impact

Yingfeng Zhang, Jin Wang, Yang Liu

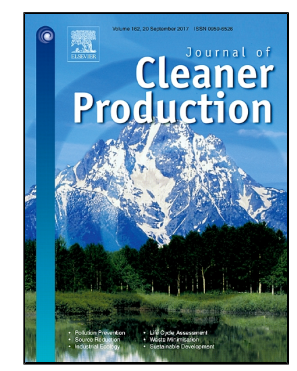

PII: S0959-6526(17)31784-5

DOI: 10.1016/j.jclepro.2017.08.068

Reference: JCLP 10326

To appear in: Journal of Cleaner Production

Received Date: 19 October 2016

Revised Date:

25 July 2017

Accepted Date:

08 August 2017

Please cite this article as: Yingfeng Zhang, Jin Wang, Yang Liu, Game theory based real-time multiobjective flexible job shop scheduling considering environmental impact, Journal of Cleaner Production (2017), doi: 10.1016/j.jclepro.2017.08.068

This is a PDF file of an unedited manuscript that has been accepted for publication. As a service to our customers we are providing this early version of the manuscript. The manuscript will undergo copyediting, typesetting, and review of the resulting proof before it is published in its final form. Please note that during the production process errors may be discovered which could affect the content, and all legal disclaimers that apply to the journal pertain. 


\title{
Game theory based real-time multi-objective flexible job shop
}

\section{scheduling considering environmental impact}

\author{
Yingfeng Zhang ${ }^{\mathrm{a},}$ *, Jin Wang ${ }^{\mathrm{a}}$, Yang Liu ${ }^{\mathrm{b}, \mathrm{c}}$ * \\ ${ }^{a}$ Key Laboratory of Contemporary Design and Integrated Manufacturing Technology, Ministry of \\ Education, Northwestern Polytechnical University, Shaanxi, P.R.China, 710072 \\ b Department of Management and Engineering, Linköping University, SE-581 83 Linköping, Sweden \\ c Department of Production, University of Vaasa, PL 700, 65101 Vaasa, Finland
}

Abstract: Production scheduling greatly contributes to optimising the allocation of processes, reducing resource and energy consumption, lowering production costs and alleviating environmental pollution. It is an effective way to progress towards green manufacturing. With the extensive use of the Internet of Things in the manufacturing shop floor, a huge amount of realtime data is created. A typical challenge is how to achieve the real-time data-driven optimisation for the manufacturing shop floor to improve energy efficiency and production efficiency. To address this problem, a dynamic game theory based two-layer scheduling method was developed to reduce makespan, the total workload of machines and energy consumption to achieve real-time multi-objective flexible job shop scheduling. To obtain an optimal solution, a sub-game perfect Nash equilibrium solution was designed. Then, a case study was employed to analyse the performance of the proposed method. The results showed that the makespan, the total workload of machines and energy consumption were reduced by $4.5 \%, 8.75 \%$, and $9.3 \%$ respectively. These improvements can contribute to sustainable development and cleaner production of manufacturing industry.

Keywords: Real-time data, Multi-objective, Flexible job shop scheduling, Dynamic game theory

\section{Introduction}

Nowadays, manufacturing, as the backbone of an industrialised society while struggling for sustainable competitive advantage (Liu, 2013; Liu and Liang, 2015), is facing other growing

\footnotetext{
${ }^{*}$ Corresponding authors.

E-mail addresses: zhangyf@nwpu.edu.cn (Yingfeng Zhang), yang.liu@liu.se (Yang Liu).
} 
1 challenges imposed by the highly demanding constraints ranging from the sustainable

development policies as well as cleaner production and green manufacturing. According to Fang et al. (2011), energy consumption in the industrial sector is approximately $50 \%$ of the total energy consumption. Every year in China, manufacturing consumes around 50\% of the entire electricity produced and generates at least $26 \%$ of the total carbon dioxide emission (Liu et al., 2014). Therefore, a principal aim of manufacturing companies is to reduce energy consumption for costsaving and environmental-friendly modes regarding the development of sustainable manufacturing. In recent years, the European Union has established a variety of environmental policies, including the restriction of hazardous substances directive (RoHS) and waste electronics and electrical equipment directive (WEEE) (Tseng et al., 2014). Recently, manufacturers have reduced the harm to the natural environment when generating waste, disrupting the ecosystem and depleting natural resources (Tseng et al., 2017). However, manufacturing companies are still reluctant, or not effective in doing so. Despite this, there has been growing interest in the improvement of energy-efficiency due to a sequence of serious environmental impacts and rising energy costs (Kang and Lee, 2016). Most existing research on reducing the energy consumption of manufacturing systems have largely centred on developing more energy-efficient machines and process redesign ( $\mathrm{Li}$ et al., 2011; Krishnan et al., 2013). However, the energy requirements for the active removal of material can be quite small, especially in the mass production environment (Dahmus and Gutowski, 2004), and it takes no more than $15 \%$ of the total energy use. It can be seen that efficiency improving efforts focusing solely on the machines or processes may miss a significant energy-efficient opportunity. Compared with machine or process redesign, production scheduling is an effective way to achieve sustainable development and cleaner production, which is beneficial to reduce resource consumption, decrease production cost and alleviate environmental pollution (Zhang and Chiong, 2016). In particular, researchers become to realise that production scheduling should play an important role in reducing the energy consumption of manufacturing shop floor. Therefore, it is natural that how to achieve cleaner production is also a part of the production scheduling problem. Energy-efficient scheduling is considered as one of the most important means for manufacturing enterprises to achieve sustainable production and reduce carbon emissions in which a lot of scholars have been attracted to investigate recently. The first two papers related to production scheduling while dealing with green objectives were written by 
1 Subaï et al., (2006). Later, Gutowski et al. (2006) showed that for different machine tools, the total

2 power required is the sum of a constant term $P_{\text {idle, }}$ which is required to run the basic functions of

3 the machine tool, such as keeping the pumps for the oil and the coolant up and running. In

4 addition, Liu and Huang (2014) studied the power consumption and carbon footprints in bath-

5 processing and parallel-processing machines by using of a genetic algorithm. However, these

6 research works are primarily concerned with developing a mathematical model for solving the static scheduling problem. Scheduling problems are dynamic in nature and complex due to uncertain events occurring in real-world production scheduling. It is evident that the previous static decision-making models of scheduling problem have some severe limitations for the real production environment, meaning that the static scheduling contributes little to energy-efficient and emission reduction in real-world manufacturing shop floor, and therefore a new dynamic model is needed.

Recently, rapid developments and widespread application of information and sensor technologies (e.g. radio frequency identification-RFID) have nurtured the emergence of manufacturing as core Advanced Manufacturing Technology (AMT) in next-generation manufacturing systems (Atzori et al., 2010). Many enterprises have adopted these technologies to implement the real-time traceability, visibility, and interoperability in improving the performance of shop floor planning, execution, and control. At present, by extending the cloud computing (CC) and Internet of Things (IoT) technologies to the industrial fields (Guo et al., 2015; Zhang et al., 2017), real-time data have become more accessible and ubiquitous, contributing to the big data environment. It makes the status of the manufacturing resources ubiquitous, and the real-time shop floor scheduling could be facilitated (Zhang et al., 2014). Thus, in a real-world manufacturing environment, the real-time data streams could challenge the traditional approaches to the multi-objective flexible job shop scheduling (MO-FJSS) problem. Moreover, it is also now technically possible to integrate IoT, smart sensors, and enhance data analytics tools with energy-efficient scheduling (Zhang et al., 2017a). For example, Pach et al. (2014) proposed a reactive scheduling approach for flexible manufacturing systems, which considered three indicators: makespan, energy consumption and the number of resource switches in a dynamic context. Cuihua et al. (2016) proposed a novel approach to simplify the scheduling problem, increase the feasibility of the scheduling result and make the manufacturing execution 
1

2

3

4

5

process more intelligent and efficient, which adopted real-time manufacturing information acquired from RFID.

Despite the significant progress achieved by researchers, the following research questions are still open in applying flexible job shop scheduling methods to the real-time manufacturing shop floor with the increasing complexity of production processes, the unpredictability of the production exceptions, etc. These questions are summarised as follows.

(1) How to use the real-time data based real-time shop floor scheduling technologies to promote cleaner production? In the existing literature about real-time scheduling, the key optimisation objectives for production decision models, such as cost, time, and quality have been widely discussed (Mosheiov and Sarig, 2010; Lu and Romanowski, 2013). However, decreasing energy consumption in manufacturing systems through real-time data based real-time scheduling has been rather limited. Therefore, a new paradigm of real-time scheduling should be proposed to utilise the newest information technologies (IoT, big data, cloud computing, artificial intelligence, etc.) on pollution prevention, and then real-time scheduling based cleaner production approaches is able to prevent the need for the end of pipe pollution control approaches.

(2) How to solve the MO-FJSS problem quickly and accurately to improve energy efficiency and production efficiency based on real-time data in the real-world environment? In the traditional MO-FJSS problem, the multi-objective optimisation approaches mainly include the Pareto optimisation, the non-dominant approach, and the weighted approach. Among them, Pareto optimisation and non-dominant approach present a set of solutions for the decision makers to choose from(Lei, 2008; Kachitvichyanukul and Sitthitham, 2011; Li et al., 2012; Liu et al., 2014a; Wang et al., 2016). However, it is economically infeasible to let decision makers choose from a large group of alternative solutions at each decision point. The weighted approach assumes that the decision maker has given the explicit definition of each objective and only optimises the total weighted values of all objectives (Bagheri et al., 2010; Rabiee et al., 2012; Xing et al., 2009). However, in the real-world environment, decision makers may not always be experienced or knowledgeable enough to define such specific weights for each objective. Therefore, it is necessary to develop a dynamic game theory of multi-objective optimisation problems to reduce the complexity of the MO-FJSS problem and improve the solving efficiency for the decision maker. 
(3) How to design a new allocation method for the MO-FJSS problem to reduce the energy consumption of production? Generally, processes of jobs are centrally assigned according to some given objectives, for example, makespan, critical machine workload, and total workload of machines (Cao and Li, 2014; Xu and Lin, 2016). However, in the real-world shop floor environment, the exceptional events, including change of production planning, machine breakdown, and production exception, are frequent in the manufacturing shop floor and lead to higher cost and energy consumption. To address this problem, there are mainly three categories of existing dynamic scheduling technologies, which are the completely reactive, the predictivereactive, and the pro-active scheduling (Ouelhadj and Petrovic, 2009). Among them, predictivereactive scheduling is the most commonly used method. It has a scheduling/rescheduling process where previous schedules are revised to adapt to the new environment caused by dynamic events. Most of the existing research generated a new schedule by minimising the effect of disruption on shop efficiency like makespan (Adibi et al., 2010; Chryssolouris and Subramaniam, 2001). However, it may produce a new schedule that is totally different from the original one. It has a serious impact on other productive activities planned based on the original schedule and brings instability and lack of continuity in the shop system (Rangsaritratsamee et al., 2004). Therefore, a new real-time MO-FJSS method needs to be considered to avoid or reduce the influence of unpredictable manufacturing exceptions based on real-time data.

To address the above challenges, in this study, a dynamic game theory model and a two-layer scheduling method were presented to address the above newly emerged problems. The dynamic game theory model was used to deal with the conflict and competition among the multiple objectives in the MO-FJSS problem. The two-layer scheduling method was used to schedule the optimal queue of the jobs for the real-time shop floor. Compared with the traditional dynamic MO-FJSS method, which used the periodic policy and event-driven policy (Adibi et al., 2010; Wang and Liu, 2015), the two-layer scheduling method can improve energy efficiency and production efficiency for the manufacturing companies. Also, a few literature has rescheduled dynamic job shops based on multi-objectives (Wang et al., 2015; Gong et al., 2016). However, some of them only considered the performances of efficiency (Adibi et al., 2010; Chryssolouris and Subramaniam, 2001; Qiu and Lau, 2013), e.g. makespan and tardiness. The others incorporated both efficiency and stability (Fattahi and Fallahi, 2010; Rangsaritratsamee et al., 
1 2004; Zhang et al., 2013). Therefore, this study filled the research gaps that the real-time multi-

2 objective scheduling for the flexible job shop of manufacturing system has not been well

3 investigated from the perspective of energy consumption reduction. Further, most existing

4 research on reducing the energy consumption of job shop scheduling has mainly centred on

5 developing the static decision-making models of scheduling problem (Liu et al., 2014; He et al.,

6 2015; Zhang and Chiong, 2016). This study presents a real-time multi-objective scheduling

7 method based on real-time production data to further improve the production efficiency and to

8 reduce the energy consumption of production. Thus, the ultimate goal of the multi-objective

9 optimisation of real-time scheduling for FJSS problem, green manufacturing, and cleaner

10 production was implemented.

11 For better understanding, the two kinds of scheduling methods are shown in Fig.1. Fig.1 (a) and 12 (b) describe the traditional scheduling method and the two-layer scheduling method based on realtime data respectively.

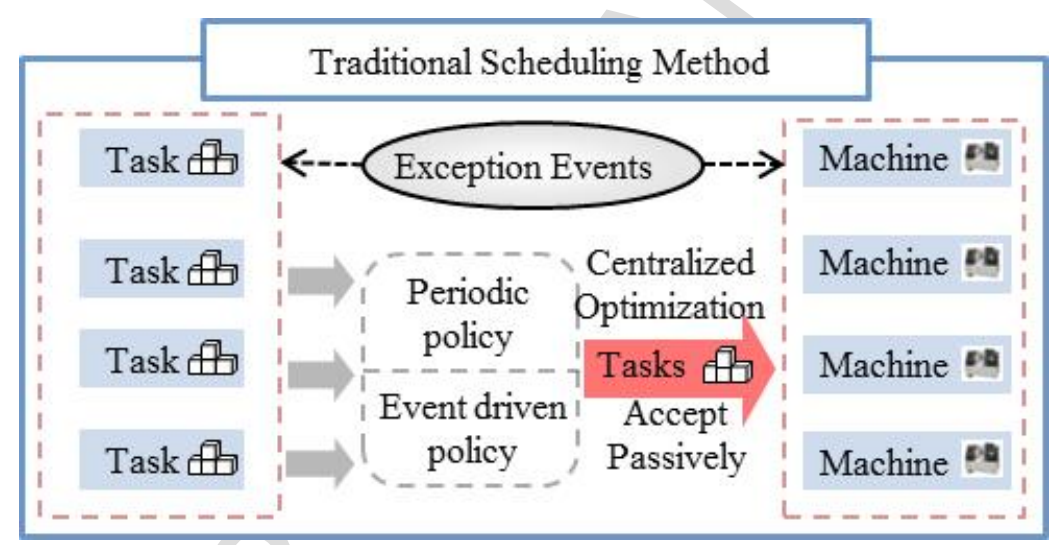

14

15

(a)

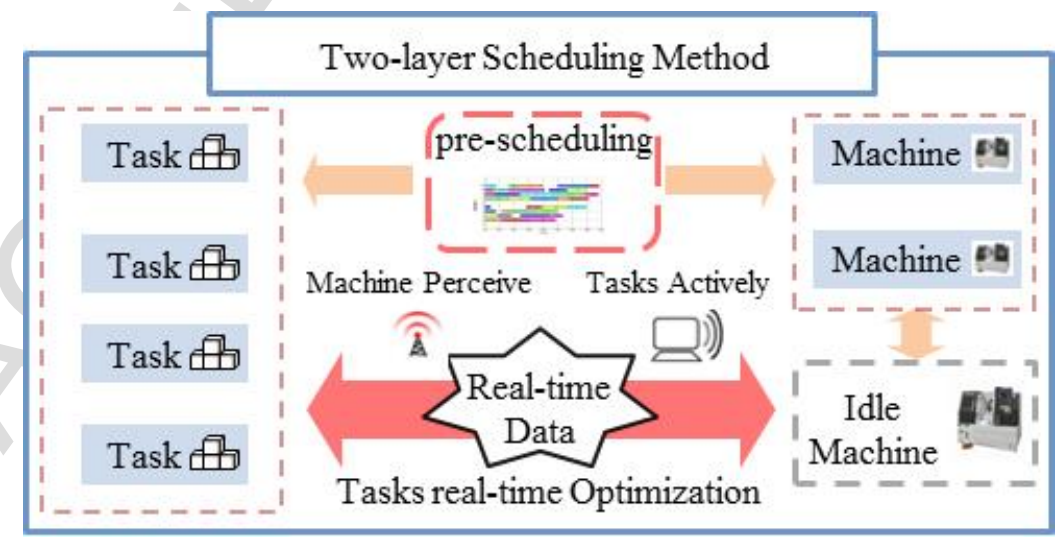

(b)

Fig.1. Comparison between two kinds of scheduling methods. (a) Traditional scheduling method (b) two-layer scheduling method

In the traditional scheduling methods, most of the approaches used the periodic policy and 
1 event-driven policy. In these two policies, at each rescheduling point which a new schedule is constructed, all the unprocessed manufacturing processes are centrally assigned to the corresponding machines. The decision model is centralised, and the machines do not interact with other distributed resources. As a result, the real-time information of distributed resource has not been considered. The performances of efficiency and energy efficiency are often decreased because of the unpredictable exceptions. Moreover, the computational complexity is higher with the increasing of machines and processes.

In the two-layer scheduling method based on real-time data, a pre-scheduling is generated at the initial time of the shop floor. Then, during the production execution stage, a real-time scheduling task pool is formed, and some processes are put into it based on the pre-scheduling results at each time. Each machine could automatically send its real-time status and request of the processes of the real-time scheduling task pool when it is idle at each time. The processes continually interact with the machines and operators according to their real-time status. Each time, only one optimal process is assigned to the requested machine. When the machine finishes the assigned process, it would automatically send its current status and request the processes again until all the processes are finished.

The two-layer scheduling method proposed has the following advantages. At any time, each machine can obtain the optimal process. The complexity of this problem is stable with the increasing of processes because only one optimal process is selected for one machine at each time by using dynamic game theory. Since the process allocation is real-time data-driven and the twolayer scheduling method is only started for the idle machine, the performances of efficiency and energy efficiency can be largely improved.

The rest of the study is organised as follows. Section 2 reviews the related literature. Real-time MO-FJSS model is discussed in Section 3. In Section 4, the dynamic game theory model of the MO-FJSS problem is presented. A two-layer scheduling method is given in Section 5. In Section 6 , a case is studied to verify the feasibility and applicability of the designed two-layer scheduling method, and an instance is tested to prove the effectiveness of the proposed algorithm. Finally, conclusions and recommendations are summarised in section 7 . 


\section{Literature review}

This study selects makespan, the total workload of machines and energy consumption as the three energy-efficient MO-FJSS optimisation objectives in the IoT-enabled flexible job shop. The IoT technology can enhance the monitoring of production processes in real-time. Therefore, the availability of real-time data gives several opportunities to reduce energy consumption by enabling and enhancing energy-efficient practices, and improve the production efficiency in production management. Improving the production efficiency can further promote the implementation of cleaner production effectively and improve the competitive advantage of manufacturing enterprises, leading to more sustainable production. In this section, we briefly review the scientific literature relative to real-time data based MO-FJSS problem considering environmental impact. The relevant literature is classified into two categories: energy-efficient scheduling and real-time MO-FJSS problem.

\subsection{Energy-efficient scheduling}

The number of previous studies regarding energy-efficient scheduling is limited but increasing. In recent years, the energy-efficient scheduling has attracted some attention (Gahm et al., 2016). To reduce energy consumption, some energy-focused optimising methods have been proposed. For the operation of a single machine, one of the earliest tries to reduce energy consumption using production scheduling can be found in the work of Mouzon et al. (2007). They developed an operational method for the minimisation of the energy consumption of manufacturing equipment and proposed a turn-on and turn-off scheduling framework. This framework has been extended for single machine scheduling in their subsequent paper (Mouzon and Yildirim, 2008). More recently, Shrouf et al. (2014) adopted the same framework to study a single machine scheduling problem to minimise the total energy consumption cost. Some studies have been carried out to address on energy optimisation for production scheduling of flow shops. Fang et al. (2013) investigated both mathematical programming and combinatorial approaches to a flow shop scheduling problem with a restriction on peak power consumption. Dai et al. (2013) proposed an energy-efficient model for flexible flow shop scheduling and adopted a genetic simulated annealing algorithm to make a significant trade-off between the makespan and the total energy consumption to implement a feasible scheduling. Mansouri et al. (2016) addressed the trade-off between energy consumption 
1 and service level, and then developed a mathematical model to minimise makespan, a measure of

2 service level and total energy consumption. Wang et al. (2017) presented one real-time energy efficiency optimisation method for energy intensive manufacturing enterprises. In their paper, the energy-related key performance indicators can be extracted timely, and the production scheduling or rescheduling activities can be obtained based on the real-time energy consumption status. Few researches are about reducing energy consumption in job shop scheduling problem. Liu et al. (2014) developed a multi-objective scheduling method with reducing energy consumption as one of the objectives. May et al. (2015) investigated the effects of production scheduling policies aimed towards improving productivity and environmental performances in a job shop system.

Thus it can be seen that energy-efficient scheduling problem are receiving increasing attention in the field of academic research and manufacturing enterprise. However, most of the current energy-efficient scheduling researches are single machine and flow shop oriented, and the above literature illustrates that current research has not sufficiently investigated energy-efficient scheduling in the flexible job shop. Also, only a handful of papers were found following a rigorous literature search. Among these, the work was done by Yang et al. (2016) seems to be the most relevant: they presented a novel method for the optimisation of bi-objective flexible job shop scheduling problem (FJSP) under stochastic processing times. In a follow-up work, Lei et al. (2017) considered FJSP with the minimisation of workload balance and total energy consumption and the conflicting between two objectives are analysed.

Therefore, from the green manufacturing point of view and particularly for energy-efficient scheduling in the flexible job shop, the research is still at a primordial state, and considerable progress has yet to come. The flexible job shop is essential to shop floor type in the real-world manufacturing industry. All the manufacturing shop floors urgently need new methods to decrease energy consumption and increase sustainability.

\subsection{Real-time MO-FJSS}

The FJSS problem is an NP-hard optimisation problem. Many different methods have been proposed to solve this issue. Brucker and Schlie (1990) were among the first to address FJSS problem. They developed a polynomial algorithm to resolve the FJSS problem with two jobs. Later, Brandimarte (1993) proposed a hybrid tabu search (TS) algorithm with some existing 
1 dispatching rules. Dauzère-Pérès and Paulli (1997) proposed a TS algorithm based on an

2 integrated approach, which was improved with two developed neighbourhood functions by

3 Mastrolilli and Gambardella (2000) regarding computation time and solution quality. In very

4 recent years, MO-FJSS problem has gained the attention of many researchers. On the methods to solve the MO-FJSS problem, they can be roughly classified into two types: weighting approach and Pareto-based approach. The existing algorithms belonging to the weighting approach include the hierarchical solution approach with particle swarm optimization (PSO) and simulated annealing (SA) (Xia and $\mathrm{Wu}, 2005$ ), genetic programming (GP) method (Tay and Ho, 2008), hybrid TS algorithm (Li et al., 2010), hybrid PSO algorithm and data mining (Karthikeyan et al., 2012). The existing algorithms belonging to the Pareto-based approach include evolutionary algorithm (Ho and Tay, 2008), self-adaptive variable neighbourhood search (VNS) (Li et al., 2012), novel path-relinking algorithm (Jia and $\mathrm{Hu}, 2014$ ), object-oriented approach along with simulated annealing optimisation algorithm(Vahit Kaplanoğlu, 2016). However, in real-world manufacturing systems, it is often the event that the working environment changes dynamically caused by the unpredictable real-time event, such as one machine fails to work suddenly, and new orders arrive in a stochastic way. Therefore, more and more approaches have been proposed in the literature to solve the dynamic MO-FJSS problem in the real-world manufacturing environment. Two common strategies for controlling production were described by Vieira et al., (2003). They pointed out that the two dynamic scheduling strategies were the predictive-reactive scheduling and reactive scheduling. With the predictive-reactive scheduling strategy, Shen and Yao (2015) developed a multi-objective evolutionary algorithm (MOEA) - based predictive-reactive method to capture the dynamic and multi-objective nature of flexible job shop scheduling. Lu et al., (2017) studied a high-performance multi-objective predictive-reactive scheduling method for the multiobjective dynamic welding scheduling problem to narrow the gap between theoretical research and applicable practice. With the reactive scheduling strategy, Yao et al., (2011) proposed a multiobjective dynamic scheduling approach that combines three attributes based on a hybrid multiple attribute decision-making technique.

Although the methods above optimise objectives efficiently, they are merely suited for the traditional manufacturing shop floor. With the development of science and technology, advanced technologies and management methods should be applied to optimise the production procedure 
1 and reduce energy consumption or environment impacts. In recent years, RFID has been widely used in supporting the production and scheduling management in manufacturing shop floor. Zhang et al., (2014b) proposed the configuration of the Internet of Manufacturing Things (IoMT) and RFID-enabled real-time data capturing and integrating framework. After capturing real-time data of manufacturing resources, instead of directly entering the optimisation stage, some adaptive controlling mechanisms are entailed to achieve the added value and management of real-time information (Qu et al., 2012). Based on value-added multi-source manufacturing data, Zhong et al. (2013) proposed an RFID-enabled real-time manufacturing execution system for a typical masscustomization production company, where RFID devices were deployed systematically on the shop floor. Therefore, manufacturing shop floor in the IoMT environment with the vast amount of data concurrency and exchange is dynamic and real-time (Zhang et al., 2017b), while the existing dynamic scheduling methods for traditional manufacturing shop floor are difficult to adapt to the IoMT environment. The real-time scheduling platform should fully consider the information exchange between the manufacturing resources, which is based on the characteristics of data and dynamic information exchange in the IoMT environment.

To address this challenge, this study proposed a two-layer scheduling method to implement real-time data-driven optimisation of energy-efficient MO-FJSS problem in the IoT-enabled flexible job shop by using dynamic game theory.

\section{Real-time MO-FJSS model}

The FJSS problem is classified as a Total FJSS problem (T-FJSS problem) and a Partial FJSS problem (P-FJSS problem) (Kacem et al., 2002). In the T-FJSS problem, each process can be processed on any machine. While in the P-FJSS problem, at least one process cannot be processed on any machine. Kacem et al. (2002) pointed out that the P-FJSS problem is more complex as compared to the T-FJSS problem on the same scale.

In this study, scheduling is assumed as the P-FJSS problem, and the mathematical model of FJSS problem is based on the dynamic game model. In this study, the following three criteria are considered to be optimised simultaneously: in order to improve the work efficiency, selecting the maximal completion time of machines, i.e., the makespan, as one objective; with a view to 
1 improve the utilization of existing resources, in particular for the machines, selecting the total

2 workload of machines, i.e., the total processing time of all machines, as the other objective; in

3 order to realise energy-efficient and emission reduction, selecting the total energy consumption of

4 production, as the last one objective.

5 To solve this problem, the following assumptions are made:

6 (1) Once a process has begun on a machine, it must not be interrupted, except for the machine breakdown. If a process is interrupted, the remaining processing time is equal to the total processing time.

(2) The transferring time of processes between different machines is negligible.

(3) The processing time includes two parts: cutting time and setup time.

Based on these assumptions, the mathematical model of the MO-FJSS problem is described as follows:

13 The notations are listed in Table 1.

Table 1 Notations

\begin{tabular}{ll}
\hline Notations & Description \\
\hline$n$ & the total number of jobs \\
$m$ & the total number of machines \\
$n_{i}$ & the total number of processes of job $i$ \\
$M=\left\{M_{1}, M_{2}, \ldots, M_{m}\right\}$ & the set of machines \\
$M_{i d l e}^{t}=\left\{M_{i}, M_{j}, \cdots, M_{l}\right\}$ & the set of the idle machine at time $t$ \\
$O_{i j}$ & the $j^{\text {th }}$ process of job $i$ \\
$O_{o p t i o n}^{t}=\left\{O_{i a}, O_{j b}, \cdots, O_{k c}\right\}$ & the set of the optional process(es) at time $t$ \\
$C_{i j k}$ & the completion time of $O_{i j}$ on $M_{k}$ \\
$C_{i j k}^{\prime}$ & the actual completion time of $O_{i j}$ on $M_{k}$ when exceptional events occur \\
$W_{t d}$ & the total workload of M \\
$W_{k}$ & the workload of $M_{k}$ \\
$E$ & the total energy consumption of production \\
$x_{i j k}$ & 1, if $M_{k}$ is selected for the $O_{i j} ; 0$, otherwise \\
$P_{0 k}$ & the idle power of $M_{k} \mathrm{KW}$ \\
$P_{k}$ & the cutting power of $M_{k} \mathrm{KW}$ \\
$t_{I k}$ & the total idle time of $M_{k}$ \\
$t_{i j k}$ & the cutting time of $O_{i j}$ operated on $M_{k}$ \\
$t_{i j k s}$ & the setup time of $O_{i j}$ operated on $M_{k}$ \\
$\theta$ & the deviation between production plan and the real-time scheduling \\
$\beta$ & the satisfaction with the confidence level \\
\hline
\end{tabular}




\begin{tabular}{ll}
\hline$O_{t}^{z}$ & the set $z$ of the temporary storage process $z \in[1,2,3]$ \\
$N u m O_{t}^{z}$ & the number of process of $O_{t}^{z}$ \\
$l$ & the $l^{t h}$-stage of a game tree \\
$N u m x^{l}$ & the total number of decision nodes in the $l^{t h}$-stage of a game tree \\
$x_{h}^{l}$ & the $h^{\text {th }}$ decision nodes in the $l^{t h}$-stage of a game tree \\
\hline
\end{tabular}

Objectives:

2 (1) Minimising the makespan, which is the maximum completion time of all the assigning processes, can be defined as:

$$
\text { Min } f_{1}=\text { Makespan }=\operatorname{Max} C_{i j k} \quad i \in[1, n], j \in\left[1, n_{i}\right], k \in[1, m]
$$

(2) Minimising the total workload of machines:

$$
\text { Min } f_{2}=W_{t d}=\sum_{k=1}^{m} W_{k}=\sum_{k=1}^{m} \sum_{i=1}^{n} \sum_{j=1}^{n_{i}}\left(t_{i j k}+t_{i j k s}\right) x_{i j k}
$$

(3) Minimising the total energy consumption of production. The total energy consumption of production model is based on existing research on energy-efficient manufacturing processes (Dai et al., 2013). The total energy consumption of production can be divided into three types: basic energy consumption, process energy consumption, and non-machining idle energy consumption. Basic energy consumption is mainly used to maintain the normal operation of the machine components, including the energy consumption of a spindle drive unit, servo feed drive unit and auxiliary components, such as cooling system, lubrication system, and lighting, etc. Process energy consumption consists of two parts: 1) idle energy consumption during job setup, such as clamping and positioning of the workpiece; 2) cutting energy consumption, corresponds to the actual cutting process. The non-machining idle energy consumption is the energy consumed by machine when they are not machining, for example waiting to job next process. In the process of production, the primary contributors to the total energy consumption are the process energy consumption and the non-machining idle energy consumption. Under this assumption, the objective of minimising the total energy consumption, which consists of the direct energy consumed, and the indirect energy consumed, can be expressed as

$$
\text { Min } f_{3}=E=\sum_{k=1}^{m} \sum_{i=1}^{n} \sum_{j=1}^{n_{i}}\left(P_{k} t_{i j k} x_{i j k}\right)+\sum_{k=1}^{m}\left(P_{0 k} t_{I k}\right)+\sum_{k=1}^{m} \sum_{i=1}^{n} \sum_{j=1}^{n_{i}}\left(P_{0 k} t_{i j k s} x_{i j k}\right)
$$
removing material in the cutting stage, and the second part on the middle and right side of the 
1 equation (3) is the indirect energy consumption, such as the non-machining idle energy

2 consumption and idle energy during job setup.

3 Subject to:

$$
C_{i, j, k} \leq C_{i, j+1, k}-t_{i, j+1, k}-t_{i, j+1, k, s} \quad j=1,2, \cdots, n_{i-1}
$$

$$
C_{i, j, k} \geq 0 \quad i=1,2, \cdots, n
$$

$$
\sum_{k \in M\left(O_{i j}\right)} x_{i j k}=1 \quad \forall i, j
$$

$$
M\left(O_{i j}\right) \subset M \quad \forall i, j
$$

The objective functions are equations (1)-(3). In this study, these three objectives have been considered for the MO-FJSS problem. Inequity (4) ensures the process precedence constraints. Equation (5) guarantees that for each process one and only one machine must be selected from the set of available machines. Formula (6) indicates that the set of available machines for each process comes from the given machine set $\mathrm{M}$.

\section{Dynamic game theory model for MO-FJSS problem}

Game theory is a useful approach to deal with the interaction of several decision makers. Recently, it has been used to solve some complex problems in various fields, such as economics, political science, and psychology. In this study, the dynamic game theory has been applied to deal with the conflict and competition among the multiple objectives in the MO-FJSS problem. In this approach, the objectives of this problem can be seen as players in the dynamic game; the dynamic game equilibrium solutions are taken as the optimal results.

\subsection{Dynamic game theory model for multi-objective optimisation problem}

A general multi-objective optimisation problem (MOP) can be summed up in the following common mode: 


$$
\left\{\begin{array}{c}
\min / \max f_{1}(x) \\
\ldots \quad \cdots \quad \cdots \\
\min / \max f_{i}(x) \\
\cdots \quad \cdots \quad \cdots \\
\min / \max f_{k}(x) \\
\text { s.t. } g_{j}(x) \leq 0, j=1, \cdots, m_{1} \\
h_{l}(x)=0, l=1, \cdots, m_{2}
\end{array}\right.
$$

2 where $x=\left(x_{1}, \cdots, x_{n}\right) \in X$ is the decision variable, $X$ is the variables space,

$3 f_{i}(x),(i=1,2, \cdots, k)$ are the cost functions, $g_{j}(x)$ and $h_{l}(x)$ together refer to as the 4 constraint functions.

5 A complete dynamic game theory model is composed of three basic elements, namely, players,

6 strategies, and utilities. Everyone knows that conflict and cooperation widely exist between the players. To apply dynamic game theory to deal with the multiple objectives, the dynamic game theory model for the MOP should be constructed.

Comparing the MOP with the dynamic game theory, the MOP can be described by dynamic game theory as follows: $k$ objectives in MOP can be described as the $k$ players in dynamic game theory; $X$ in MOP can be described as the decision strategy space $S$ in dynamic game theory; $f_{i}(x),(i=1,2, \cdots, k)$ in MOP can be described as the utility function $u_{i}$ in dynamic game theory, $g_{j}\left(x_{1}, \cdots, x_{n}\right)$ and $h_{l}\left(x_{1}, \cdots, x_{n}\right)$ in MOP can be described as the constraints in dynamic game theory.

Defining mapping $\phi_{i}: i^{t h} \rightarrow p_{i}$ as the $p_{i}$ player; defining mapping $\phi_{i}: X \rightarrow S_{i}$ as the decision strategies space of the $p_{i}$ player and $\cup_{i=1}^{k} S_{i}=X$; defining mapping $\phi_{i}: f_{i} \rightarrow u_{i}$ as the utility of the $p_{i}$ player, and then the dynamic game theory model of the MOP can be defined as follows:

$$
G=\{P ; S ; U\}=\left\{p_{1}, p_{2}, \cdots, p_{k} ; S_{1}, S_{2}, \cdots S_{k} ; u_{1}, u_{2}, \cdots, u_{k}\right\}
$$

\subsection{Sub-game perfect Nash equilibrium and MOP}

Dynamic game equilibrium essentially is a sub-game perfect Nash equilibrium, which is an important concept in the non-cooperative dynamic game theory. A dynamic game of complete 
1 information may have much Nash equilibrium, but some of these may involve non-credible threats or promises. The sub-game perfect Nash equilibrium (SPNE) is those that pass a credibility test.

The SPNE can be defined as follows: $s^{*}=\left(s_{1}^{*}, \cdots, s_{i}^{*}, \cdots, s_{n}^{*}\right)$ is a strategy set of the game in

4 Eq. (8), if (1) $s^{*}$ is the Nash equilibrium of the original game, (2) $s^{*}$ constitute a Nash

5 equilibrium in every sub-game, $s^{*}=\left(s_{1}^{*}, \cdots, s_{i}^{*}, \cdots, s_{n}^{*}\right)$ can be seen as one SPNE solution in this game.

Therefore, for the MOP (Eq. (7)), $f_{i}(x),(i=1,2, \cdots, k)$ can be regarded as the $k$ players in a dynamic game. Decision strategies space $S$ equals to variables space $X$. And the utility function for each player is $f_{i}(s)$. The SPNE solution $s^{*}=\left(s_{1}^{*}, \cdots, s_{i}^{*}, \cdots, s_{n}^{*}\right)$ can be seen as one solution of the MOP (Eq.(7)).

\subsection{Dynamic game theory for MO-FJSS problem}

To use the dynamic game theory to deal with the multiple objectives in the MO-FJSS problem, the dynamic game theory model for the MO-FJSS problem should be constructed. In this study, the MO-FJSS problem has three objectives. They can be seen as three players in the dynamic game. Here, players take actions sequentially, and the choice of the former player has an effect on the selection of the latter because the latter can observe the action of the former first and then make a choice. The utility function of the first player is the first objective function which corresponds to the makespan $\left(u_{I}=f_{I}\right)$, the utility function of the second player is the second objective function which corresponds to the total machine workload $\left(u_{2}=f_{2}\right)$, and the utility function of the third player is the third objective function which corresponds to the total energy consumption $\left(u_{3}=f_{3}\right)$. The dynamic game theory model for the MO-FJSS problem can be described as follows:

$$
G=\left\{f_{1}, f_{2}, f_{3} ; S ; u_{1}, u_{2}, u_{3}\right\}
$$

The sub-game perfect Nash equilibrium solution of this model is taken as the optimal result of the MO-FJSS problem. 


\section{A two-layer scheduling method for real-time MO-FJSS problem}

Based on the dynamic game theory model for MO-FJSS problem designed in Section 4, a twolayer scheduling method is devised in this section to reduce the complexity of the real-time MOFJSS problem and improve the solving efficiency for the real-time decision. In the two-layer scheduling method, the first layer is the pre-optimised layer, which is used to generate a prescheduling as a production planning. The second layer is the real-time scheduling layer, which is used to schedule the processes based on pre-scheduling result under the real-time workshop environment at each time. The objective of this two-layer scheduling method is to optimise a series of production processes based on the real-time data. Details of these two layers are described as follows.

\subsection{Pre-optimised layer}

Pre-optimization for the production processes is used to generate a production planning for realtime scheduling by using dynamic game theory under static condition. It could avoid data redundancy because there are too many production processes need to be scheduled in the real-time scheduling layer. All the production processes are pre-optimised according to the SPNE of three objectives. The dynamic game theory based pre-optimised method can be implemented through the following steps described in Fig.2.

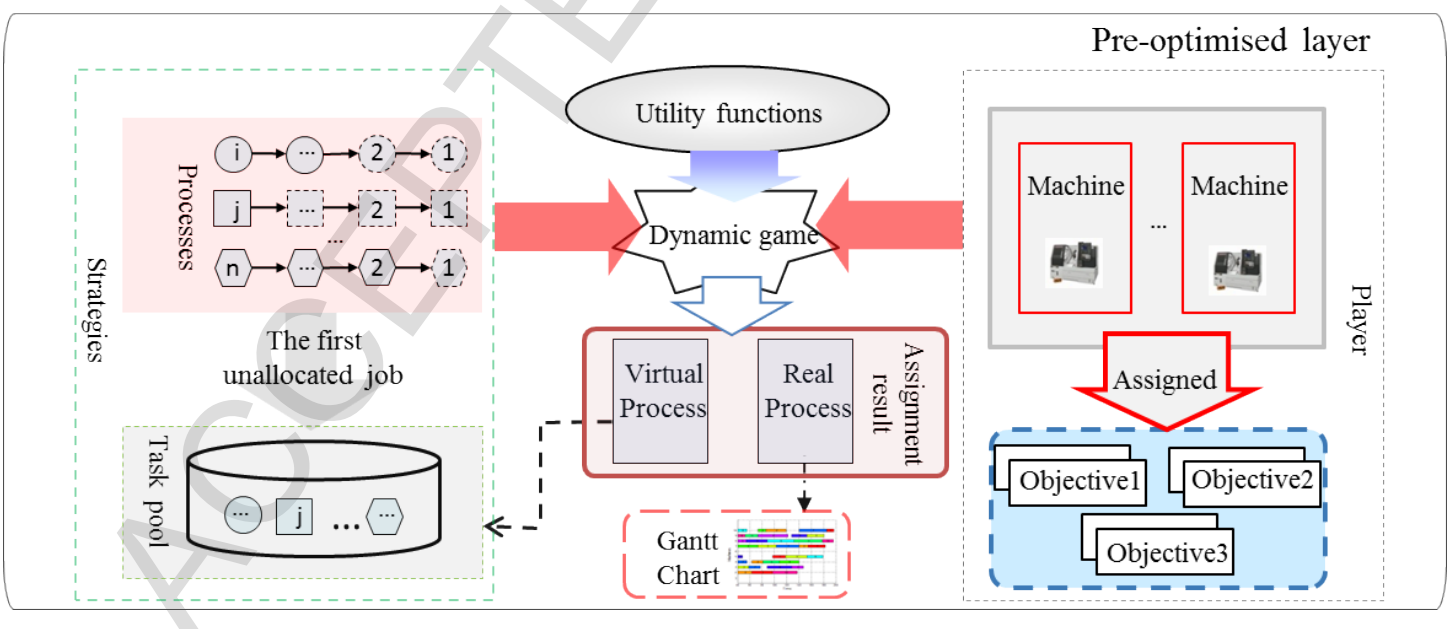

Fig.2.The procedures for implementing the pre-optimization layer

Step 1: All machines are assigned to three objectives in turn. For example, $M_{l}$ is for $f_{l}$ and $M_{2}$ is for $f_{2}$ and so on. In a real-world manufacturing system, the number of machines is greater than three, so we can assign $M_{4}$ to $f_{l}$ and $M_{5}$ to $f_{2}$ until all machines are allocated to finish. 
Step 2: Three objectives correspond to three players. Each player makes a decision independent of another player.

Step 3: Construct a task pool and put the first unallocated processes of each job into it. The processes in the task pool called the strategies of the players. So, each machine which is assigned to the $f_{i}(i=1,2,3)$ could choose the corresponding process of the task pool.

Step 4: Calculate the utility functions $u_{l}(s), u_{2}(s)$ and $u_{3}(s)$ of the player1, 2, 3 according to Eqs. (1)-(3) respectively from each feasible combination of strategies.

Step 5: Construct a dynamic game procedure and solve the SPNE by a backwards induction, which will be described in detail in Section 5.3.

Step 6: Based on the result of SPNE, some processes in the task pool are assigned to the machines. If a process meets the following allocated rules in Fig.3, it is known as a real process and is added to the prepared processing queue of the machine. Otherwise, the process is known as a virtual process and is put back into the task pool.

\section{//The steps of allocation rules}

Input: The assigned result of the processes based on the SPNE.

Start

For each $O_{i j}$ which is assigned to each $M_{k}$

If $t_{i j k}+t_{i j k s}<t_{i j l}+t_{i j / s}(l=1,2, k-1, k+1, \cdots, m)$

Put each $O_{i j}$ into $O^{1}$

If Num $O_{t}^{1}$ is greater than one

$\left\{\right.$ Choose $O_{i j} \in O_{t}^{1}$ of earliest completion time and put into $O_{t}^{2}$

If Num $O^{2}$ is more than one

\{Choose $O_{i j} \in O_{t}^{2}$ which belongs to the machine that the process of the prepared processing sequence is the least and put into $O_{t}^{3}$

If $\mathrm{Num} \mathrm{O}_{t}^{3}$ is still greater than one

Selection one $O_{i j}$ from $O_{t}^{3}$ randomly and the $O_{i j}$ is added to the prepared processing sequence of the $M_{k}$

Else $O_{i j} \in O_{t}^{3}$ is added to the prepared processing sequence of the $M_{k}$

\}

Else $O_{i j} \in O_{t}^{2}$ is added to the prepared processing sequence of the $M_{k}$ \}

Else $O_{i j} \in O_{t}^{1}$ is added to the prepared processing sequence of the $M_{k}$

Clear $O_{t}^{z}$.

End

Output: Only one process is added to the prepared processing queue of the machine in the end. 
These steps are repeated until all processes are added to the prepared processing queue of the appropriate machines. In the pre-optimised layer, the output is a processing queue of processes to every $M_{k}$. This output determines which process should be allocated at each time $\mathrm{t}$ in real-time scheduling layer.

\subsection{The real-time scheduling layer}

In the pre-optimised layer, the prepared processing queue of each machine is determined. To rapidly respond to the exception and get an optimal process queue in the real-time workshop environment, this section describes that how each process is assigned to the most optimal machine by using the dynamic game theory at each time t. Based on the dynamic game theory, the procedure of the real-time scheduling is shown in Fig.4.

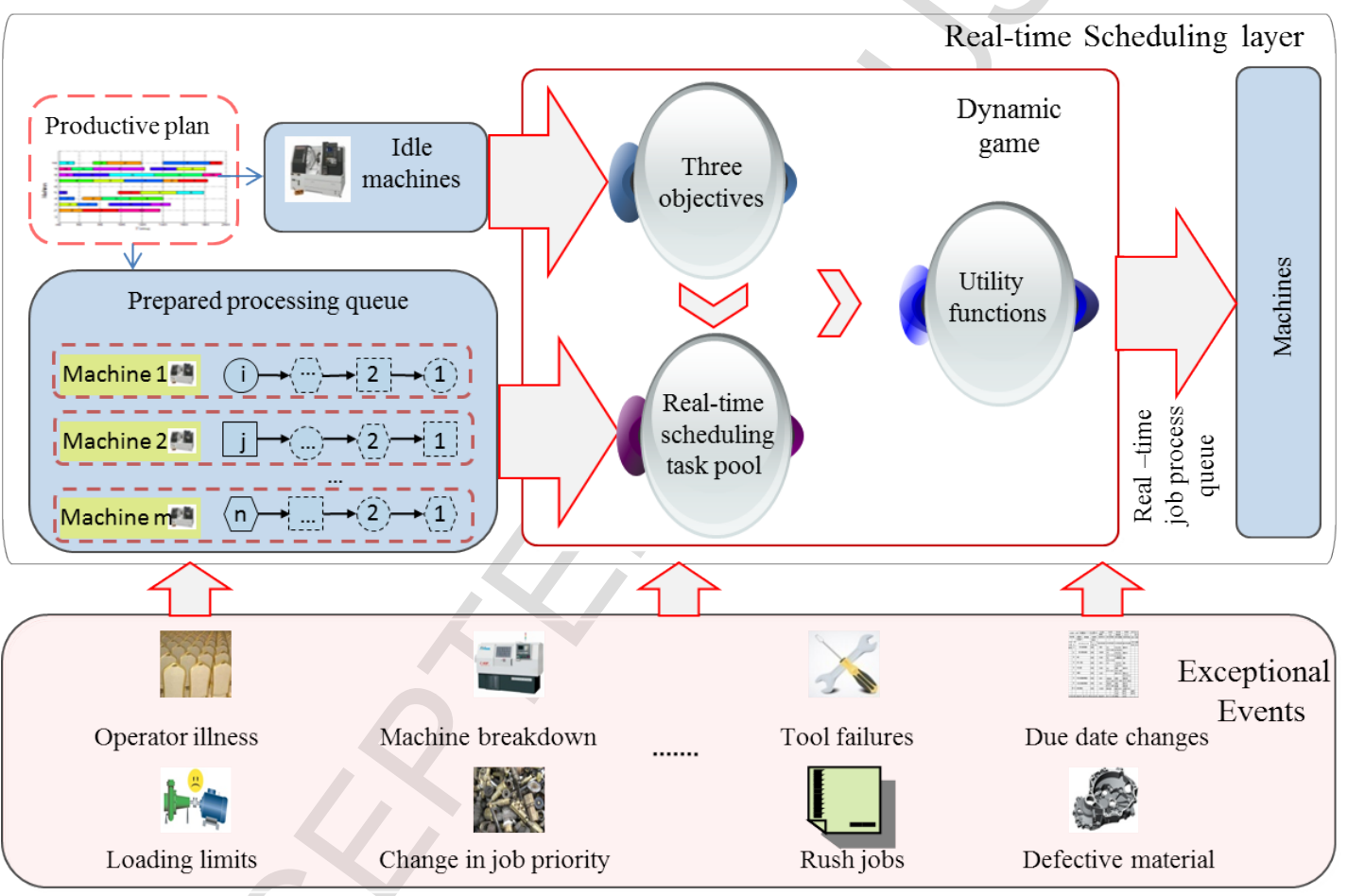

Fig.4. The procedures for implementing the real-time scheduling layer

During each time $t$ of the implementation of the production planning, a dynamic game theory based real-time scheduling method is triggered so that the processes can be assigned to the most suitable machines or operators according to the real-time workshop environment. The aim of realtime scheduling layer is to finish all processes from the pre-optimised layer. Each time $t$, the major steps could be described as follows:

Step 1: $M_{\text {idle }}^{t}$ are assigned to three objectives in turn, and three objectives correspond to three 
1 players.

2 Step 2: Construct a real-time scheduling task pool and put $O_{\text {option }}^{t}$ into it. Here, $O_{\text {option }}^{t}$ meet the 3 following two conditions:

(1) Ensure the processes precedence constraints of jobs;

(2) Ensure the prepared processing queue precedence constraining of the pre-scheduling result 6 on each $M_{k}$.

The processes in the real-time scheduling task pool are called the strategies of the players.

Therefore, $M_{i d l e}^{t}$ which is assigned to the $f_{i}$ could choose the corresponding process from the real-

9 time scheduling task pool.

Step 3: Calculate the utility functions $\mathrm{u}_{1}(\mathrm{~s}), \mathrm{u}_{2}(\mathrm{~s})$ and $\mathrm{u}_{3}(\mathrm{~s})$ according to Eqs. (1)-(3) respectively from each feasible combination of strategies.

Step 4: Construct the dynamic game procedure and solve the SPNE, which will be described in detail in Section 5.3. Then the processes of $O_{\text {option }}^{t}$ are assigned to the most suitable machines or operators in an optimal way according to their real-time status.

Step 5: In the next time $t(t=t+1)$, repeat Step 1 to Step 4 until finish all the jobs.

The output of real-time scheduling layer is the real-time job process queue. Each machine follows this output by using the real-time status information. At time $t$, if exceptional events (e.g., machine breakdown and the change of the order) occur in a real-time scheduling workshop, the following strategy can be adopted to deal with exceptional events, and the procedure of the strategy is shown in Fig.5.

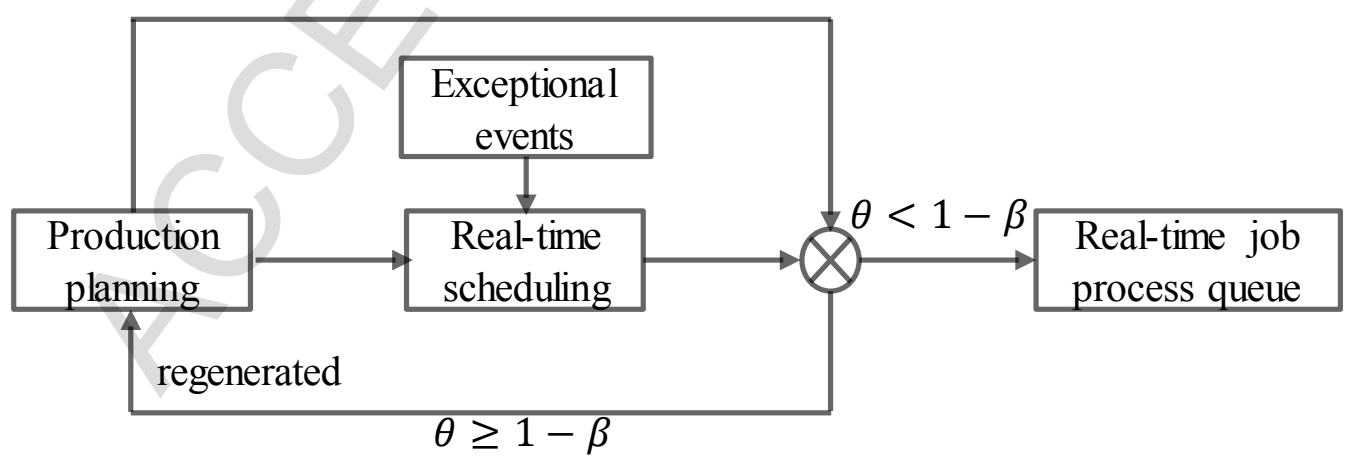

Fig.5. The procedure of the strategy when exceptional events occur

Firstly, the real-time scheduling is implemented considering the exceptional events. To evaluate the effect of exceptional events on the production planning, $\theta$, which is the deviation between 
1 production planning and the real-time scheduling, is given as follows.

2

$$
\theta=\sum_{i=1}^{n} \sum_{j=1}^{n_{i}} \frac{\left|C_{i j k}^{\prime}-C_{i j k}\right|}{C_{i j k}} x_{i j k} \quad k \in[1, m]
$$

According to the historical data, $\beta$ as satisfaction with the confidence level is set.

Secondly, if $\theta<1-\beta$, exceptional events are considered the small exceptional events which have little effect on the production planning. So the influence brought by the exceptions can be timely eliminated through changing the players or the strategies of the dynamic game theory according to the method proposed in this section. If the $\theta \geq 1-\beta$, the exceptional events are considered the big exceptional ones which have much effect on the production planning. So the production planning needs to be regenerated according to the method referred in Section 5.1 which only considers the unprocessed processes. Then, real-time scheduling executes again according to the method referred in this section, and the processes can be assigned to the most suitable machines under the real-time workshop environment.

\subsection{SPNE solution}

For non-cooperative static games, Nash equilibrium is broadly known as the solution point at which every player has no reason to change his behaviour. In our non-cooperative dynamic game of complete and perfect information, we apply the extended solution concept of SPNE to analyse the strategic behaviour of the players, i.e., the makespan, the total workload of machines and the total energy consumption of production in the extensive form, which involves a tree structure with several nodes and branches, providing an explicit description of the order of play and the information available to each player at the time of his decision. A complete extensive form of our game is in Fig. 6. There are k-stages, and each stage has one player that would make a decision. In this game, three objectives $f_{1}, f_{2}$, and $f_{3}$ correspond to three players and the processes called the strategies of the players. 


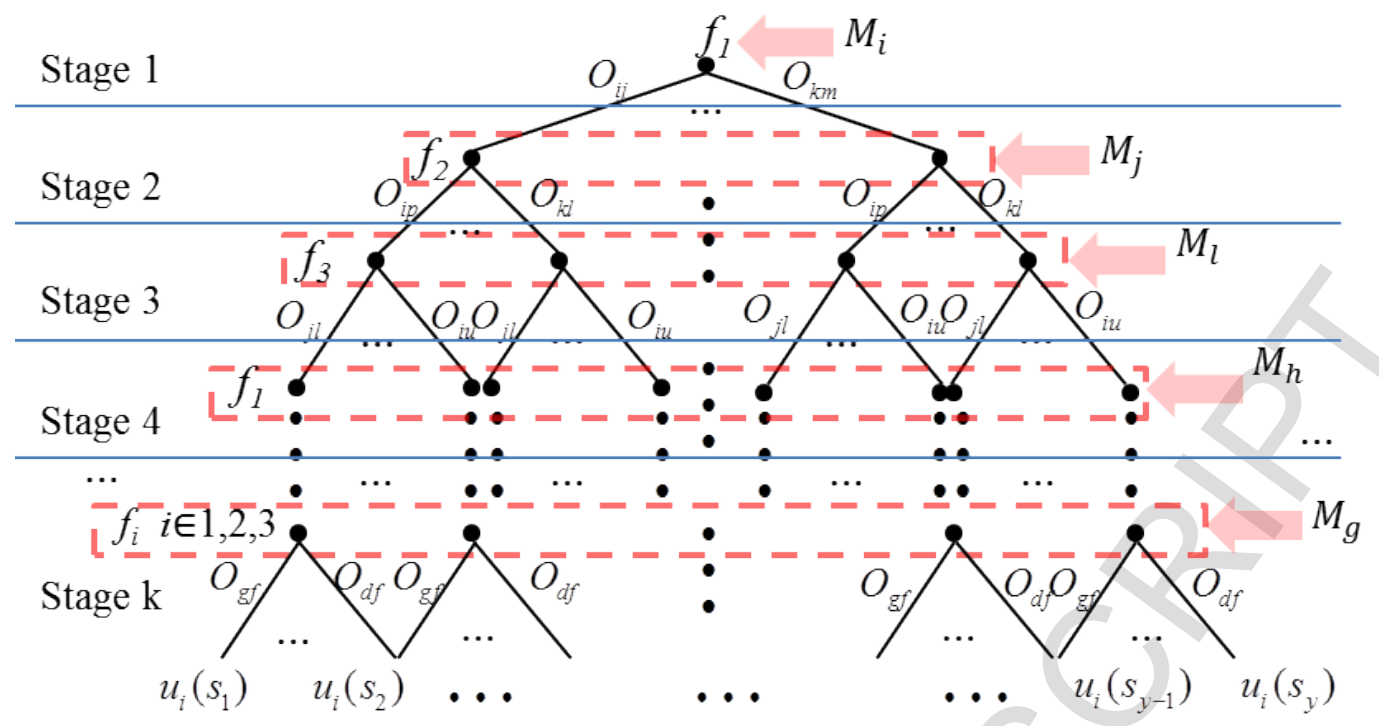

Fig.6. Game tree representation of the game

In this study, we propose a solution procedure based on the technique of backwards induction which can be used to find an SPNE. Once strategies are assigned at each stage, we can calculate the corresponding payoff for each other. Then, we can determine an SPNE according to each player's utility using backwards induction. The solution algorithm is briefly summarised in Fig. 7.

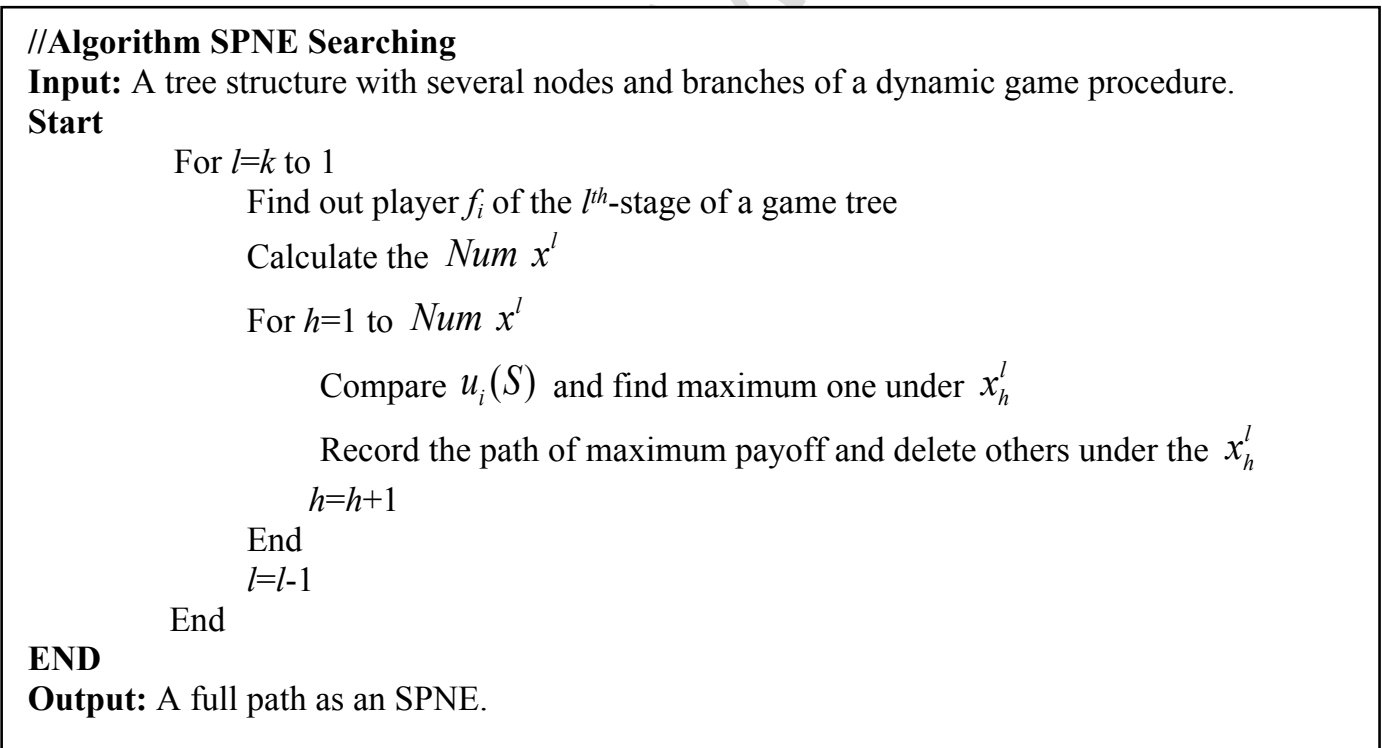

Fig.7. Solution procedure

\section{Case study}

\subsection{Method of solving the real-time MO-FJSS problem}

A real-time MO-FJSS problem is described in this section to illustrate the dynamic game theory based a two-layer scheduling method designed in this study. 
1 The designed real-time MO-FJSS problem is based on Kacem's instance (Kacem et al., 2002),

2 which is a problem $8 \times 8$ that consists of 27 processes of eight jobs which can be processed on eight

3 machines. In our instance, job 9 is a rush order as an exceptional event during the production

4 execution stage. The detailed information of jobs is shown in Table 2. Symbol '-' indicates that

5 the assignment is impossible. We only need to switch symbol '-' to infinity, such as 999 . By this

6 way, the partial flexibility problem can be converted to a total flexibility issue.

7 Compared with Kacem's instance, to optimise the total energy consumption of production, we

8 present the cutting power for the processes on different machines and divide the processing time

9 into setup time and the cutting time. In Table 2, the three numbers $(\mathrm{x}, \mathrm{y}, \mathrm{z})$ in Row $\mathrm{O}_{\mathrm{ij}}$ and Column

$10 M_{k}$ means that the setup time of process ' $\mathrm{j}$ ' in job ' $\mathrm{i}$ ' done by machine ' $\mathrm{k}$ ' is ' $\mathrm{x}$ ', and the cutting

11 time is ' $y$ ' and the cutting power is ' $\mathrm{z}$ '. For example, $(1 / 2 / 1.8)$ of row $\mathrm{O}_{11}$ in column $\mathrm{M}_{2}$ means

12 that the setup time of process ' 1 ' of the job ' 1 ' in the machine ' 2 ' is ' 1 ', the cutting time is ' 2 ' and

13 the cutting power is ' 1.8 '. Table 3 gives the idle power of each machine abstracted from research

14 works developed by (He et al., 2015). The time unit is defined as an hour, and the parameter $\beta$ is

150.8

16 Table 2 The instance of real-time MO-FJSS problem

\begin{tabular}{|c|c|c|c|c|c|c|c|c|c|}
\hline Jobs & Processes & $\mathrm{M}_{1}$ & $\mathrm{M}_{2}$ & $\mathrm{M}_{3}$ & $\mathrm{M}_{4}$ & $\mathrm{M}_{5}$ & $\mathrm{M}_{6}$ & $\mathrm{M}_{7}$ & $\mathrm{M}_{8}$ \\
\hline \multirow{3}{*}{$\mathrm{J}_{1}$} & $\mathrm{O}_{11}$ & $1 / 4 / 1.3$ & $1 / 2 / 1.8$ & $1 / 4 / 3.2$ & $2 / 1 / 1.1$ & $1 / 2 / 1.1$ & - & $4 / 6 / 0.8$ & $2 / 7 / 1.1$ \\
\hline & $\mathrm{O}_{12}$ & $2 / 8 / 1.3$ & - & $2 / 3 / 3.4$ & $3 / 5 / 3.2$ & $1 / 2 / 0.8$ & $3 / 6 / 0.8$ & $4 / 5 / 0.9$ & $2 / 4 / 1.3$ \\
\hline & $\mathrm{O}_{13}$ & - & $3 / 7 / 1.8$ & & $2 / 3 / 1.4$ & $4 / 2 / 0.7$ & $1 / 1 / 0.9$ & $2 / 2 / 1.2$ & $3 / 2 / 1.3$ \\
\hline \multirow{4}{*}{$\mathrm{J}_{2}$} & $\mathrm{O}_{21}$ & $2 / 3 / 1.6$ & $4 / 3 / 2.1$ & $2 / 1 / 2.6$ & $2 / 7 / 1.5$ & $1 / 7 / 1.2$ & - & $5 / 4 / 1.1$ & - \\
\hline & $\mathrm{O}_{22}$ & - & $3 / 5 / 2.4$ & $1 / 4 / 2.4$ & $1 / 1 / 1.6$ & $2 / 4 / 1.4$ & $2 / 5 / 1.2$ & $2 / 8 / 1.3$ & $1 / 8 / 1.4$ \\
\hline & $\mathrm{O}_{23}$ & - & $4 / 6 / 2.3$ & - & $2 / 3 / 1.5$ & $5 / 1 / 0.9$ & $2 / 2 / 1.8$ & $0.5 / 0.5 / 1.4$ & $3 / 4 / 1.3$ \\
\hline & $\mathrm{O}_{24}$ & $3 / 7 / 1.4$ & $3 / 5 / 1.8$ & $2 / 7 / 2.4$ & $4 / 2 / 3.2$ & $1 / 4 / 0.8$ & $3 / 4 / 1.7$ & - & - \\
\hline \multirow{3}{*}{$\mathrm{J}_{3}$} & $\mathrm{O}_{31}$ & $3 / 7 / 2.1$ & & - & $1 / 6 / 1.5$ & $3 / 3 / 0.7$ & $4 / 1 / 1.6$ & $1 / 1 / 1.3$ & $3 / 1 / 1.2$ \\
\hline & $\mathrm{O}_{32}$ & 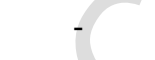 & 2/8/1.9 & $1 / 5 / 2.6$ & $3 / 1 / 1.6$ & $2 / 6 / 1.2$ & $5 / 4 / 1.7$ & $2 / 8 / 1.4$ & - \\
\hline & $\mathrm{O}_{33}$ & $0.5 / 0.5 / 1.4$ & $1 / 3 / 2.5$ & $2 / 3 / 4.2$ & $2 / 4 / 1.4$ & - & $2 / 8 / 1.3$ & - & $2 / 5 / 0.8$ \\
\hline \multirow{3}{*}{$\mathrm{J}_{4}$} & $\mathrm{O}_{41}$ & $1 / 2 / 1.3$ & $0.2 / 0.8 / 2.4$ & $2 / 4 / 3.2$ & $1 / 4 / 2.1$ & $2 / 7 / 1.3$ & $3 / 4 / 1.7$ & $5 / 3 / 1.3$ & $2 / 2 / 1.1$ \\
\hline & $\mathrm{O}_{42}$ & $3 / 9 / 1.4$ & $4 / 7 / 2.6$ & $3 / 4 / 4.2$ & $5 / 3 / 3.2$ & $2 / 8 / 1.5$ & $3 / 2 / 0.8$ & $5 / 1 / 1.2$ & $3 / 6 / 1.3$ \\
\hline & $\mathrm{O}_{43}$ & $2 / 2 / 1.4$ & $4 / 2 / 3.7$ & $1 / 1 / 3.2$ & $3 / 7 / 1.5$ & $2 / 1 / 0.8$ & $2 / 7 / 0.7$ & $4 / 1 / 1.4$ & $2 / 5 / 1.8$ \\
\hline \multirow{4}{*}{$\mathrm{J}_{5}$} & $\mathrm{O}_{51}$ & $1 / 2 / 1.3$ & $2 / 4 / 1.2$ & $3 / 4 / 2.4$ & $4 / 4 / 1.2$ & $4 / 5 / 0.8$ & - & $4 / 6 / 1.3$ & - \\
\hline & $\mathrm{O}_{52}$ & $2 / 8 / 1.2$ & - & $3 / 4 / 2.8$ & $3 / 1 / 2.1$ & $2 / 7 / 1.3$ & $5 / 3 / 0.7$ & $4 / 2 / 1.3$ & - \\
\hline & $\mathrm{O}_{53}$ & - & $3 / 6 / 3.2$ & $2 / 6 / 3.2$ & $2 / 5 / 1.8$ & $1 / 3 / 1.2$ & $1 / 1 / 1.2$ & $2 / 5 / 1.4$ & - \\
\hline & $\mathrm{O}_{54}$ & $2 / 9 / 2.1$ & $2 / 6 / 1.6$ & - & $2 / 4 / 1.7$ & $4 / 3 / 1.5$ & $2 / 3 / 1.3$ & $2 / 1 / 1.3$ & $2 / 4 / 1.3$ \\
\hline \multirow{3}{*}{$\mathrm{J}_{6}$} & $\mathrm{O}_{61}$ & $1 / 5 / 1.4$ & $2 / 5 / 1.7$ & $0.3 / 0.7 / 4.2$ & $1 / 3 / 1.6$ & $2 / 4 / 0.8$ & $2 / 7 / 1.4$ & - & $3 / 7 / 1.3$ \\
\hline & $\mathrm{O}_{62}$ & $4 / 7 / 1.3$ & - & $3 / 6 / 3.2$ & $2 / 7 / 1.4$ & $5 / 4 / 0.9$ & $2 / 5 / 0.9$ & $1 / 5 / 1.3$ & $2 / 2 / 1.3$ \\
\hline & $\mathrm{O}_{63}$ & $5 / 5 / 1.4$ & $2 / 3 / 2.1$ & $4 / 5 / 2.4$ & $3 / 7 / 1.5$ & $2 / 9 / 1.2$ & - & $2 / 8 / 1.2$ & - \\
\hline
\end{tabular}




\begin{tabular}{|c|c|c|c|c|c|c|c|c|c|}
\hline \multirow{3}{*}{$\mathrm{J}_{7}$} & $\mathrm{O}_{71}$ & $2 / 3 / 1.1$ & $2 / 2 / 2.2$ & $1 / 1 / 3.2$ & $2 / 4 / 1.3$ & $4 / 3 / 1.3$ & - & $2 / 8 / 0.8$ & - \\
\hline & $\mathrm{O}_{72}$ & - & $4 / 5 / 2.5$ & - & $5 / 4 / 1.4$ & $6 / 5 / 0.8$ & $2 / 7 / 1.6$ & $2 / 8 / 1.3$ & $2 / 3 / 1.4$ \\
\hline & $\mathrm{O}_{73}$ & - & $2 / 6 / 2.4$ & $4 / 5 / 4.2$ & $3 / 1 / 1.2$ & $3 / 5 / 1.2$ & $2 / 4 / 2.1$ & - & $5 / 5 / 1.6$ \\
\hline \multirow{4}{*}{$\mathrm{J}_{8}$} & $\mathrm{O}_{81}$ & $1 / 1 / 1.4$ & $1 / 7 / 3.2$ & $2 / 3 / 2.2$ & $2 / 7 / 1.4$ & - & $1 / 3 / 1.2$ & - & $3 / 7 / 1.8$ \\
\hline & $\mathrm{O}_{82}$ & $2 / 5 / 1.3$ & $2 / 2 / 1.7$ & $3 / 4 / 2.9$ & $4 / 4 / 1.4$ & $4 / 5 / 1.1$ & - & $2 / 8 / 1.3$ & - \\
\hline & $\mathrm{O}_{83}$ & 2/7/1.4 & $2 / 7 / 3.2$ & - & $6 / 2 / 1.2$ & $3 / 2 / 0.8$ & $5 / 1 / 1.3$ & $2 / 5 / 1.4$ & $0.5 / 0.5 / 1.3$ \\
\hline & $\mathrm{O}_{84}$ & $4 / 5 / 1.7$ & - & $1 / 2 / 4.1$ & $4 / 3 / 1.2$ & $0.2 / 0.8 / 0.9$ & $2 / 3 / 1.4$ & $2 / 6 / 0.9$ & - \\
\hline \multirow{3}{*}{$\mathrm{J}_{9}$} & $\mathrm{O}_{91}$ & $2 / 3 / 1.3$ & $2 / 5 / 2.4$ & $4.2 / 4 / 3.2$ & $3.2 / 2 / 1.1$ & $4.2 / 1 / 1.1$ & - & $3.2 / 4 / 1.6$ & $2.2 / 2 / 1.2$ \\
\hline & $\mathrm{O}_{92}$ & $2 / 2 / 1.6$ & $2 / 5 / 2.3$ & $4.2 / 10 / 2$ & $2.2 / 2 / 1.2$ & $1.2 / 3 / 1.3$ & $2.2 / 4 / 1.1$ & - & $3.2 / 7 / 1.3$ \\
\hline & $\mathrm{O}_{93}$ & $1 / 4 / 1.2$ & $1 / 3 / 2.2$ & $4.2 / 2 / 3.2$ & $3.2 / 8 / 1.3$ & $2.2 / 5 / 2.1$ & $3.2 / 10 / 1.3$ & $1.2 / 4 / 1.3$ & $3.2 / 2 / 1.5$ \\
\hline
\end{tabular}

1 Table 3 Idle power of machines

\begin{tabular}{ccccccccc}
\hline$M_{k}$ & $\mathrm{M}_{1}$ & $\mathrm{M}_{2}$ & $\mathrm{M}_{3}$ & $\mathrm{M}_{4}$ & $\mathrm{M}_{5}$ & $\mathrm{M}_{6}$ & $\mathrm{M}_{7}$ & $\mathrm{M}_{8}$ \\
\hline Idle power [KW] & 0.995 & 1.485 & 1.91 & 0.6 & 0.43 & 0.56 & 0.47 & 0.72 \\
\hline
\end{tabular}

The flow of dynamic game theory based a two-layer scheduling method in this case includes

3 three main steps and they are described as follows:

4 At first, all jobs will be added to the prepared processing queue of machines to generate a pre-

5 scheduling as a production planning for further real-time scheduling according to the initial

6 condition. For each process, the relevant machines compete for it considering the three objectives

7 simultaneously, i.e. minimising the makespan (denoted by $f_{l}$ ), the total workload of machines

8 (denoted by $f_{2}$ ), and the total energy consumption of production (denoted by $f_{3}$ ), according to the

9 method referred in Section 5.1. Fig. 8 shows the pre-scheduling result of data in Table 2 and Table

103 at the initial time of the shop floor under static condition. According to Fig. 8, the processes of a

11 prepared processing queue of each machine precedence constraints are given in Table 4 for the

12 real-time scheduling layer.

13

14

15

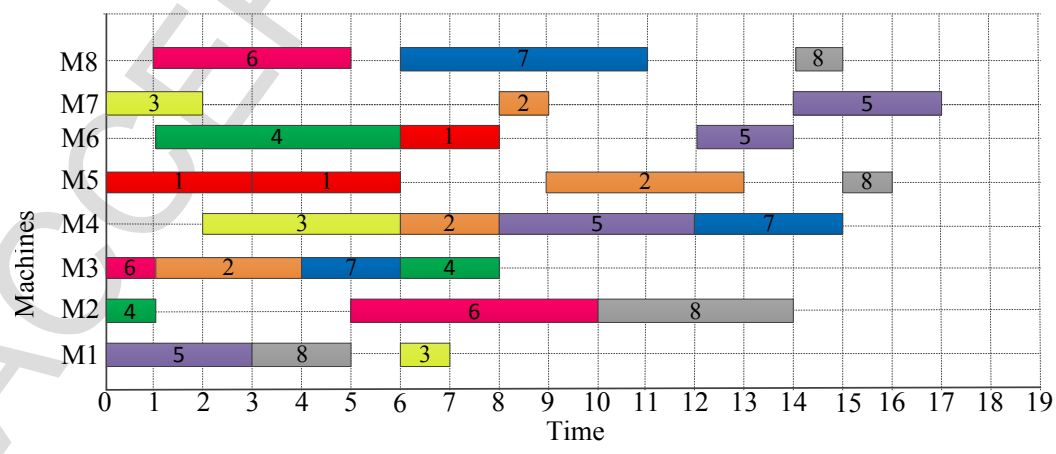

Fig.8. Pre-scheduling results of Table 2 and Table 3

Table 4 The prepared processing queue of each machine

\begin{tabular}{ccccc}
\hline Machine & First & Second & Third & Fourth \\
\hline $\mathrm{M}_{1}$ & $\mathrm{O}_{51}$ & $\mathrm{O}_{81}$ & $\mathrm{O}_{33}$ & \\
$\mathrm{M}_{2}$ & $\mathrm{O}_{41}$ & $\mathrm{O}_{63}$ & $\mathrm{O}_{82}$ & \\
\hline
\end{tabular}




\begin{tabular}{lllll}
\hline $\mathrm{M}_{3}$ & $\mathrm{O}_{61}$ & $\mathrm{O}_{21}$ & $\mathrm{O}_{71}$ & $\mathrm{O}_{43}$ \\
$\mathrm{M}_{4}$ & $\mathrm{O}_{32}$ & $\mathrm{O}_{22}$ & $\mathrm{O}_{52}$ & $\mathrm{O}_{73}$ \\
$\mathrm{M}_{5}$ & $\mathrm{O}_{11}$ & $\mathrm{O}_{12}$ & $\mathrm{O}_{24}$ & $\mathrm{O}_{84}$ \\
$\mathrm{M}_{6}$ & $\mathrm{O}_{42}$ & $\mathrm{O}_{13}$ & $\mathrm{O}_{53}$ & \\
$\mathrm{M}_{7}$ & $\mathrm{O}_{31}$ & $\mathrm{O}_{23}$ & $\mathrm{O}_{54}$ & \\
$\mathrm{M}_{8}$ & $\mathrm{O}_{62}$ & $\mathrm{O}_{72}$ & $\mathrm{O}_{83}$ & \\
\hline
\end{tabular}

1 After all the processes of all the jobs are added to the prepared processing queue of machines,

2 during each time $t$ of the implementation of the production planning, a dynamic game theory

3 based real-time scheduling method is triggered so that the process can be assigned to the most

4 suitable machines or operators under the real-time workshop environment according to the method

5 referred in Section 5.2. Table 5 shows the procedure of real-time scheduling without considering

6 the exceptional events, and the Gantt chart of the real-time scheduling is same as the pre-

7 scheduling results which are shown in Fig. 8.

8 Table 5 The procedure of real-time scheduling without considering the exceptional events

\begin{tabular}{|c|c|c|c|}
\hline Time & Idle machines & Optional process(es) & Real-time scheduling result(s) \\
\hline 0 & $\left\{\mathrm{M}_{1}, \mathrm{M}_{2}, \mathrm{M}_{3}, \mathrm{M}_{4}, \mathrm{M}_{5}, \mathrm{M}_{6}, \mathrm{M}_{7}, \mathrm{M}_{8}\right\}$ & $\left\{\mathrm{O}_{11}, \mathrm{O}_{31}, \mathrm{O}_{41}, \mathrm{O}_{51}, \mathrm{O}_{61}\right\}$ & $\mathrm{O}_{11} \rightarrow \mathrm{M}_{5} ; \mathrm{O}_{31} \rightarrow \mathrm{M}_{7} ; \mathrm{O}_{41} \rightarrow \mathrm{M}_{2} ; \mathrm{O}_{51} \rightarrow \mathrm{M}_{1} ; \mathrm{O}_{61} \rightarrow \mathrm{M}_{3}$ \\
\hline 1 & $\left\{\mathrm{M}_{2}, \mathrm{M}_{3}, \mathrm{M}_{4}, \mathrm{M}_{6}, \mathrm{M}_{8}\right\}$ & $\left\{\mathrm{O}_{21}, \mathrm{O}_{42}, \mathrm{O}_{62}\right\}$ & $\mathrm{O}_{21} \rightarrow \mathrm{M}_{3} ; \mathrm{O}_{42} \rightarrow \mathrm{M}_{6} ; \mathrm{O}_{62} \rightarrow \mathrm{M}_{8}$ \\
\hline 2 & $\left\{\mathrm{M}_{2}, \mathrm{M}_{4}, \mathrm{M}_{7}\right\}$ & $\left\{\mathrm{O}_{32}\right\}$ & $\mathrm{O}_{32} \rightarrow \mathrm{M}_{4}$ \\
\hline 3 & $\left\{\mathrm{M}_{1}, \mathrm{M}_{2}, \mathrm{M}_{5}, \mathrm{M}_{7}\right\}$ & $\left\{\mathrm{O}_{12}, \mathrm{O}_{81}\right\}$ & $\mathrm{O}_{12} \rightarrow \mathrm{M}_{5} ; \mathrm{O}_{81} \rightarrow \mathrm{M}_{1}$ \\
\hline 4 & $\left\{\mathrm{M}_{2}, \mathrm{M}_{3}, \mathrm{M}_{7}\right\}$ & $\left\{\mathrm{O}_{71}\right\}$ & $\mathrm{O}_{71} \rightarrow \mathrm{M}_{3}$ \\
\hline 5 & $\left\{\mathrm{M}_{1}, \mathrm{M}_{2}, \mathrm{M}_{7}, \mathrm{M}_{8}\right\}$ & $\left\{\mathrm{O}_{63}\right\}$ & $\mathrm{O}_{63} \rightarrow \mathrm{M}_{2}$ \\
\hline 6 & $\left\{\mathrm{M}_{1}, \mathrm{M}_{3}, \mathrm{M}_{4}, \mathrm{M}_{5}, \mathrm{M}_{6}, \mathrm{M}_{7}, \mathrm{M}_{8}\right\}$ & $\left\{\mathrm{O}_{13}, \mathrm{O}_{22}, \mathrm{O}_{33}, \mathrm{O}_{43}, \mathrm{O}_{72}\right\}$ & $\mathrm{O}_{13} \rightarrow \mathrm{M}_{6} ; \mathrm{O}_{22} \rightarrow \mathrm{M}_{4} ; \mathrm{O}_{33} \rightarrow \mathrm{M}_{1} ; \mathrm{O}_{43} \rightarrow \mathrm{M}_{3} ; \mathrm{O}_{72} \rightarrow \mathrm{M}_{8}$ \\
\hline 7 & None & None & None \\
\hline 8 & $\left\{\mathrm{M}_{1}, \mathrm{M}_{3}, \mathrm{M}_{4}, \mathrm{M}_{5}, \mathrm{M}_{6}, \mathrm{M}_{7}\right\}$ & $\left\{\mathrm{O}_{52}, \mathrm{O}_{23}\right\}$ & $\mathrm{O}_{52} \rightarrow \mathrm{M}_{4} ; \mathrm{O}_{23} \rightarrow \mathrm{M}_{7}$ \\
\hline 9 & $\left\{\mathrm{M}_{1}, \mathrm{M}_{3}, \mathrm{M}_{5}, \mathrm{M}_{6}, \mathrm{M}_{7}\right\}$ & $\left\{\mathrm{O}_{24}\right\}$ & $\mathrm{O}_{24} \rightarrow \mathrm{M}_{5}$ \\
\hline 10 & $\left\{\mathrm{M}_{1}, \mathrm{M}_{2}, \mathrm{M}_{3}, \mathrm{M}_{6}, \mathrm{M}_{7}\right\}$ & $\left\{\mathrm{O}_{82}\right\}$ & $\mathrm{O}_{82} \rightarrow \mathrm{M}_{2}$ \\
\hline 11 & None & None & None \\
\hline 12 & $\left\{\mathrm{M}_{1}, \mathrm{M}_{3}, \mathrm{M}_{4}, \mathrm{M}_{6}, \mathrm{M}_{7}, \mathrm{M}_{8}\right\}$ & $\left\{\mathrm{O}_{53}, \mathrm{O}_{73}\right\}$ & $\mathrm{O}_{53} \rightarrow \mathrm{M}_{6} ; \mathrm{O}_{73} \rightarrow \mathrm{M}_{4}$ \\
\hline 13 & None & None & None \\
\hline 14 & $\left\{\mathrm{M}_{1}, \mathrm{M}_{2}, \mathrm{M}_{3}, \mathrm{M}_{5}, \mathrm{M}_{6}, \mathrm{M}_{7}, \mathrm{M}_{8}\right\}$ & $\left\{\mathrm{O}_{54}, \mathrm{O}_{83}\right\}$ & $\mathrm{O}_{54} \rightarrow \mathrm{M}_{7} ; \mathrm{O}_{83} \rightarrow \mathrm{M}_{8}$ \\
\hline 15 & $\left\{\mathrm{M}_{1}, \mathrm{M}_{2}, \mathrm{M}_{3}, \mathrm{M}_{5}, \mathrm{M}_{6}, \mathrm{M}_{8}\right\}$ & $\left\{\mathrm{O}_{84}\right\}$ & $\mathrm{O}_{84} \rightarrow \mathrm{M}_{5}$ \\
\hline
\end{tabular}

During the production execution stage, the real-time manufacturing information is captured by machines, and the job information is also accessible to them. If exceptional events occur at time t, through the corresponding strategy referred in Section 5.2, the real-time scheduling can implement 12 continuously according to the changed manufacturing environment.

13 In this case, four kinds of exceptional events, i.e. the unexpected machine breakdown, the rush 14 orders, the cancelled orders, and the quality defect, are involved to illustrate the real-time 
1 scheduling method.

2 For the first exception, machine 5 broke down at time $t_{1}\left(t_{1}=3\right)$. The recovered time of the 3 machine is $t_{2}\left(t_{2}=6\right)$. As shown in Fig. 9 (a), the exception is captured by Machine 5.

4 Consequently, machine 5 loses the capability to compete for any processes. For the second

5 exception, job 9 is added at time $t_{3}\left(t_{3}=6\right)$. As seen in Fig. 9 (b), the exception is captured by all 6 machines which could compete for job 9 from time $t_{3}$. For the third exception, job 6 is cancelled at

7 time $t_{4}\left(t_{4}=3\right)$. This exception is highlighted on job 6 , and all the processes of job 6 are ignored, as

8 is illustrated in Fig. 9 (c). For the fourth exception, $O_{22}$ is inspected and is proven to be rejected

9 the product. As Fig. 9 (d) shows, this exception is captured by $O_{22}$. So $O_{22}$ will be put back into 10 real-time scheduling task pool again at time $t_{5}\left(t_{5}=8\right)$.

11

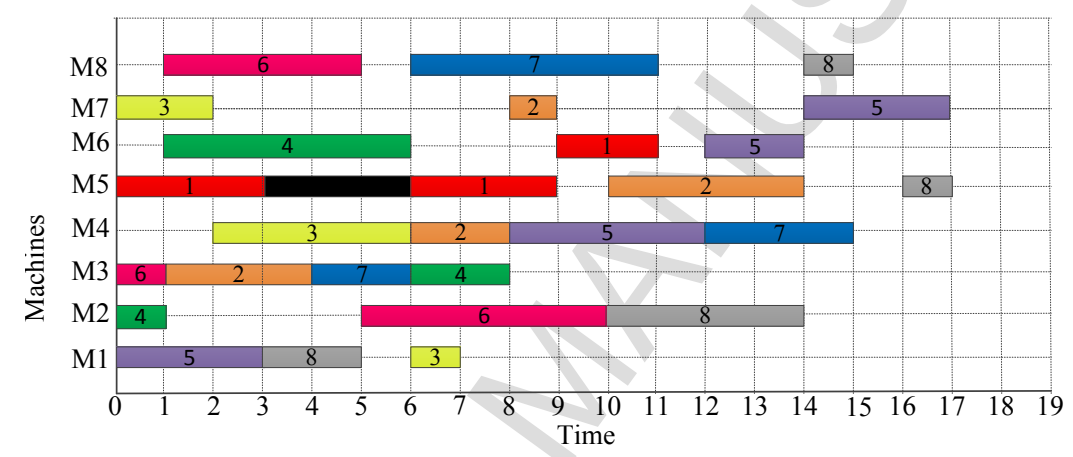

(a)

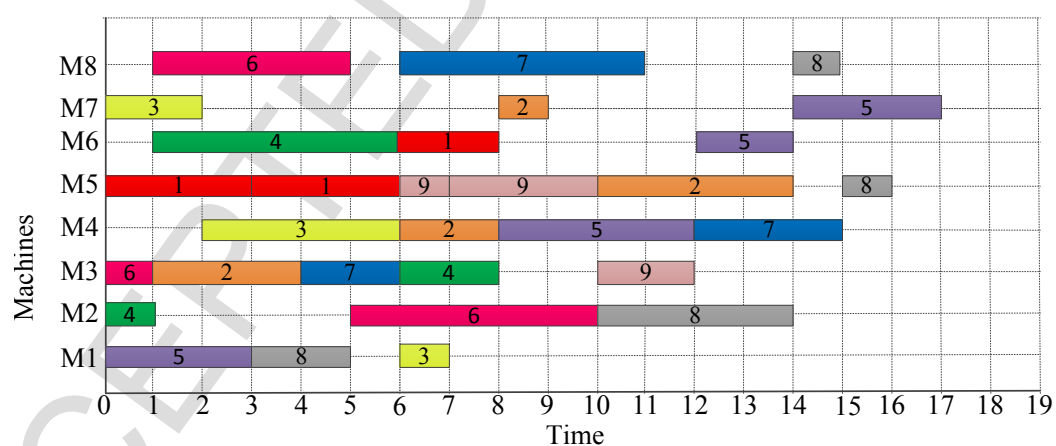

(b)

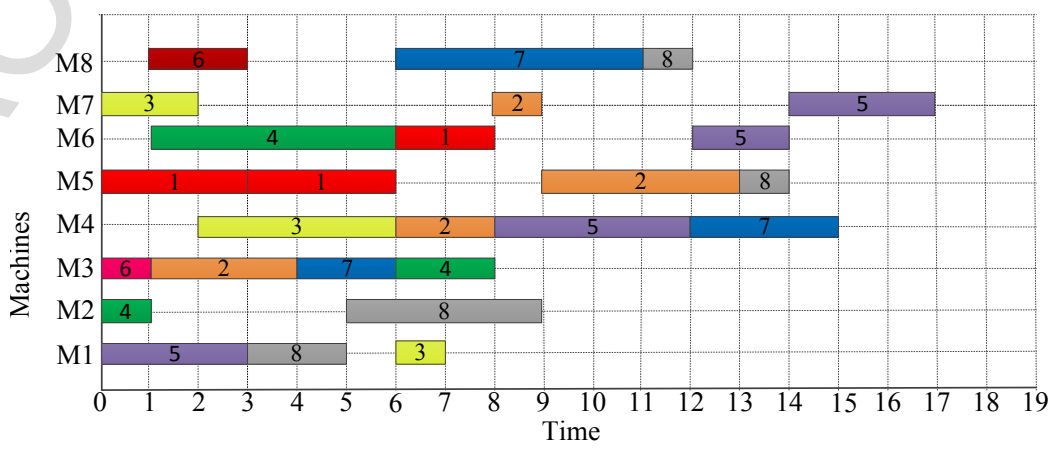


(c)

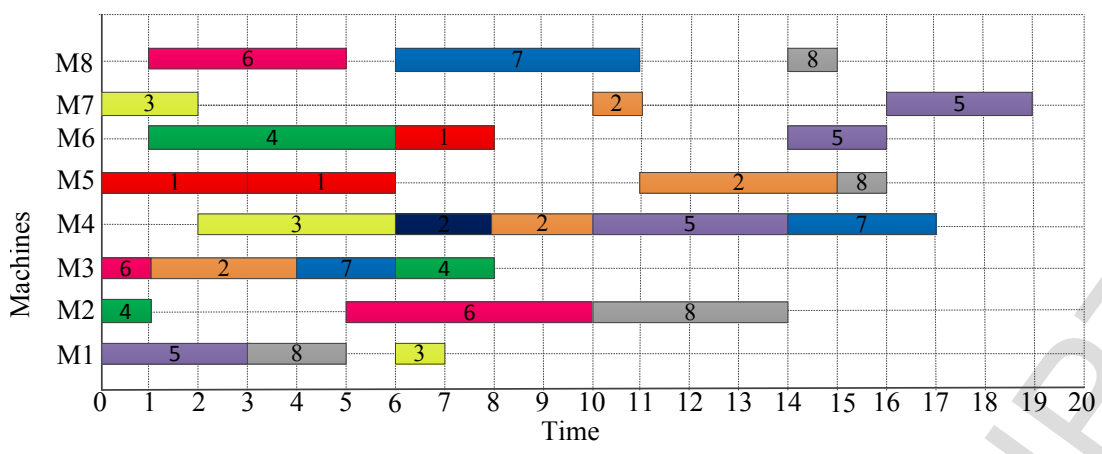

(d)

Fig.9. Real-time scheduling in four exceptional conditions

\subsection{Experiment, results and analyses}

To demonstrate the effectiveness of our proposed approach in solving the MO-FJSS problem considering the total energy consumption of production, the following comparison experiment has been carried out. Scenario 1 represents a scheduling created the following some well-established traditional scheduling approaches without considering reducing the total energy consumption of production as an objective. Being set as the control group and baseline, scenario 1 corresponds to the FJSS problem with the bi-objective to minimise the makespan and the total workload of machines. The existing weighted approaches including AL+CGA (Kacem et al., 2002), PSO+TS (Zhang et al., 2009), and Pareto-based approaches including hybrid sorting immune simulated annealing algorithm (HSISAT) (Shivasankaran et al., 2015) have been used as the optimisation techniques in this scenario. For the Kacem's instance (problem $8 \times 8$ ), when there are no exceptional events occur, the makespan and the total workload of machines have been given after each run of the optimisation technique. The total energy consumption of production has been calculated based on each optimised scheduling, as shown in Table 6. For the two-layer scheduling method, the values of the three objective functions are compared with the solutions in scenario 1 (a bi-objective FJSS problem), the results of which are also listed in Table 6.

From Table 6 , the scheduling obtained by our proposed approach has better $W_{T}$ compared to the other two algorithms. For our proposed approach solutions, $W_{T}$ is 73 hours while in the $\mathrm{AL}+\mathrm{CGA}$ and PSO+TS it is 75 hours and 77 hours. The minimum improvement is $2.67 \%$, and the maximum improvement is $5.2 \%$. According to Table $6, C_{M}$ is slightly increased in our approach solutions compared to other three algorithms. However, the total energy consumption of production 
1 obtained by our proposed approach is $111.48 \mathrm{kWh}$, which means that the minimum improvement

2 is $5.3 \%$, and the maximum improvement is $8 \%$ compared to other three algorithms. It can be seen

3 that our proposed approach solutions outperform other three algorithms regarding the total energy

4 consumption of production. Thus, it can be concluded that the proposed a two-layer scheduling

5 method is effective to realise the tri-objective optimisation to minimise the makespan, the total

6 workload of machines and the total energy consumption of production in the flexible job shop

7 under static condition.

Table 6. Results of kacem instances

\begin{tabular}{|c|c|c|c|c|}
\hline Objectives & $\mathrm{AL}+\mathrm{CGA}$ & $\mathrm{PSO}+\mathrm{TS}$ & HSISAT & $\begin{array}{l}\text { urs proposed } \\
\text { approach }\end{array}$ \\
\hline$C_{M}$ [hour] & 16 & 14 & 16 & 17 \\
\hline$W_{T}$ [hour] & 75 & 77 & 73 & 73 \\
\hline$E \quad[\mathrm{kWh}]$ & 117.59 & 117.67 & 121.18 & 111.48 \\
\hline
\end{tabular}

With the aim of further validating the effectiveness of the proposed dynamic game theory based a two-layer scheduling method considering the exceptional events under the real-time workshop environment in the MO-FJSS problem, we compared it with several traditional dynamic scheduling methods, such as a GA+periodic scheduling method by Fang and Xi, (1997) and completely reactive scheduling methods, which assign processes to optimal machines according to a specific machine assignment rule, and once a machine becomes idle, and there are processes in its waiting queue, it chooses the process with the highest priority to process based on a heuristic priority dispatching rule (Shen and Yao, 2015).

Here, three popular priorities dispatching rules (PDRs) are employed, including Short Processing Time (SPT), Most Operations Remaining (MOPNR) and Least Flexible Job (LFJ). If exceptional events occur, there may be some processes which need to be assigned to an available machine. For example, the processes of the new arrival jobs, and some previously unavailable process become available again due to the machine repairs. We consider three machine assignment rules (MARs) for such processes. The first one finds the available machine with the minimum processing time for each process. The second one assigns each process to its alternative machine which has the minimum workload currently. The third one chooses an alternative machine at random for each process. We call them MAR1, MAR2, and MAR3 in short.

To demonstrate the real-time scheduling procedure, a scenario with random exceptions is 
1 discussed based on the above case. In this scenario, four exceptions are involved during the

2 production execution stage, i.e., $M_{1}, M_{3}, M_{6}$ and $M_{8}$ breakdown at time $t_{1}=4, t_{2}=5, t_{3}=6, t_{4}=7$, and

3 the recovery time are $t_{5}=6 t_{6}=7, t_{7}=8, t_{8}=9$ respectively. Table 7 shows the comparisons of the

4 results of the scenario with four exceptions.

5 Table 7 Comparisons of the dynamic game theory based a two-layer scheduling method against

6

\begin{tabular}{|c|c|c|c|}
\hline Scheduling methods & $C_{M}[$ hour $]$ & $W_{T}[$ hour $]$ & $E[\mathrm{kWh}]$ \\
\hline MAR1+SPT & 23 & 96 & 151.59 \\
\hline MAR2+SPT & 32 & 136 & 217.01 \\
\hline MAR3+SPT & 31 & 115 & 189.19 \\
\hline MAR1+MOPNR & 26 & 119 & 194.93 \\
\hline MAR2+ MOPNR & 37 & 156 & 256.9 \\
\hline MAR3+ MOPNR & 29 & 118 & 183.31 \\
\hline MAR1+LFJ & 26 & 124 & 170.7 \\
\hline MAR2+ LFJ & 37 & 156 & 261.11 \\
\hline MAR3+ LFJ & 27 & 125 & 177.89 \\
\hline $\mathrm{GA}+$ periodic scheduling & 22 & 80 & 138.44 \\
\hline Our proposed approach & 21 & 73 & 125.62 \\
\hline
\end{tabular}

According to Table 7 , the minimum and maximum values of $C_{M}$ obtained by the traditional scheduling methods are 22 hours and 37 hours respectively, which mean that it achieves the minimum $4.5 \%$ and maximum $43.2 \%$ improvement in $C_{M}$ compared with our proposed method. For our proposed method solutions, $W_{T}$ is 73 hours. However, in the traditional scheduling methods, the best solution is 80 hours, and the worst solution is 156 hours. The minimum improvement is $8.75 \%$, and the maximum improvement is $53.2 \%$. Compared with the traditional scheduling methods, $E$ is decreased from the maximum value $261.11 \mathrm{kWh}$ and the minimum value 138.44kWh to $125.62 \mathrm{kWh}(-51.9 \%$ and $-9.3 \%)$. Thus, based on the experimental results and key observations, it can be seen that the critical parameters influencing the efficiency of the MO-FJSS problem could be improved significantly by using advanced IoT technologies and optimisation method.

\section{Conclusions and future work}

The rapid progress of information and communication technology will provide flexible job shop scheduling system with strong supports to implement real-time information based cleaner production. However, there are still difficulties in using the real-time data to develop the dynamic 
1 decision support systems for improving the performance of shop floor planning, execution, and

control. In this study, a dynamic game model is formalised for the tri-objective flexible job shop problem, which considers both factors of production (i.e. makespan and the total workload of machines) plus environmental influence (i.e. the total energy consumption of production). Then, the IoT-based two-layer scheduling method is proposed to provide a new paradigm for manufacturing enterprises to enhance their efficiency of production scheduling and reduce the processing cost with minimised energy consumption by using dynamic game theory. The performance of the method has been tested on the Kacem's instance. Also, the comparison experiments have been applied to demonstrate the effectiveness of the two-layer scheduling method and the presented dynamic game model in solving the MO-FJSS problem.

Two major contributions are highlighted in this study. The first one is the real-time scheduling method. Contrast to the traditional centralised allocation method, the real-time scheduling method is proposed. The machine can actively request for processes when they are available at each time, and the real-time scheduling task pool will timely assign the optimal processed to the distributed machines according to their real-time status. The second contribution is the proposal of the dynamic game optimisation model for the multi-objective problem. Targeting at minimising the makespan, and the total workload of machines, and reducing the energy consumption of production, a dynamic game theory based model is designed to improve the production efficiency further and to reduce the processing cost. Compared with the GA+ periodic scheduling method whose solutions are the best in traditional scheduling method, the proposed dynamic game theory based a two-layer scheduling method solutions for MO-FJSS problem minimizing the makespan($4.5 \%)$, the total workload of machines $(-8.75 \%)$ and the total energy consumption of production (9.3\%) were implemented under the real-time workshop environment. These improvements can contribute to sustainable development and green production of manufacturing industry.

Further research is proposed to focus on the improvement of methodologies to solve the realtime production scheduling system with more objectives and practical constraints. In addition, how to integrate the advantages of multi-agent and auto-ID technologies to implement real-time shop floor scheduling also needs to be taken into consideration. 


\section{Acknowledgements}

2 The authors gratefully acknowledge the financial supports of National Science Foundation of 3 China (51675441), the Fundamental Research Funds for the Central Universities (Grant number $4 \quad 3102017 \mathrm{jc} 04001$ ), and the 111 Project Grant (B13044). This study is also supported in part by the 5 Circularis (Circular Economy through Innovating Design) project (Grant No. 2016-03267) and the 6 Simon (New Application of AI for Services in Maintenance towards a Circular Economy) project 7 (Grant No. 2017-01649) funded by VINNOVA, Sweden's Innovation Agency.

\section{References}

Adibi, M.A., Zandieh, M., Amiri, M., 2010. Multi-objective scheduling of dynamic job shop using variable neighborhood search. Expert Syst. Appl. 37, 282-287. doi:10.1016/j.eswa.2009.05.001

Atzori, L., Iera, A., Morabito, G., 2010. The Internet of Things: A survey 54, 2787-2805. doi:10.1016/j.comnet.2010.05.010

Bagheri, A., Zandieh, M., Mahdavi, I., Yazdani, M., 2010. An artificial immune algorithm for the flexible job-shop scheduling problem. Futur. Gener. Comput. Syst. doi:10.1016/j.future.2009.10.004

Brandimarte, P., 1993. Routing and scheduling in a flexible job shop by tabu search. Ann. Oper. Res. 41, 157-183. doi:10.1007/BF02023073

Brucker, P., Schlie, R., 1990. Job-shop scheduling with multi-purpose machines. Computing 45, 369375. doi:10.1007/BF02238804

Cao, H., Li, H., 2014. Simulation-based approach to modeling the carbon emissions dynamic characteristics of manufacturing system considering disturbances. J. Clean. Prod. doi:10.1016/j.jclepro.2013.10.002

Chryssolouris, G., Subramaniam, V., 2001. Dynamic scheduling of manufacturing job shops using genetic algorithms. J. Intell. Manuf. 12, 281-293. doi:10.1023/A:1011253011638

Cuihua, C., Sheng, L., Pengfei, L., Lu, W., 2016. Active shop scheduling of production process based on RFID technology. doi:10.1051/matecconf20164204004

Dahmus, J.B., Gutowski, T.G., 2004. An Environmental Analysis of Machining, in: ASME International Mechanical Engineering Congress and RD\&D Expo. pp. 1-10. doi:10.1115/IMECE2004-62600

Dai, M., Tang, D., Giret, A., Salido, M.A., Li, W.D., 2013. Energy-efficient scheduling for a flexible flow shop using an improved genetic-simulated annealing algorithm. Robot. Comput. Integr. Manuf. 29, 418-429. doi:10.1016/j.rcim.2013.04.001

Dauzère-Pérès, S., Paulli, J., 1997. An integrated approach for modeling and solving the general multiprocessor job-shop scheduling problem using tabu search. Ann. Oper. Res. 70, 281-306. doi:10.1023/A:1018930406487

Fang, J., Xi, Y., 1997. A rolling horizon job shop rescheduling strategy in the dynamic environment. Int. J. Adv. Manuf. Technol. 13, 227-232. doi:10.1007/BF01305874

Fang, K., Uhan, N.A., Zhao, F., Sutherland, J.W., 2013. Flow shop scheduling with peak power consumption constraints. Ann. Oper. Res. 206, 115-145. doi:10.1007/s10479-012-1294-z

Fang, K., Uhan, N., Zhao, F., Sutherland, J.W., 2011. A new approach to scheduling in manufacturing for power consumption and carbon footprint reduction, in: Journal of Manufacturing Systems. pp. 
234-240. doi:10.1016/j.jmsy.2011.08.004

Fattahi, P., Fallahi, A., 2010. Dynamic scheduling in flexible job shop systems by considering simultaneously efficiency and stability. CIRP J. Manuf. Sci. Technol. 2, 114-123. doi:10.1016/j.cirpj.2009.10.001

Gahm, C., Denz, F., Dirr, M., Tuma, A., 2016. Energy-efficient scheduling in manufacturing companies: A review and research framework. Eur. J. Oper. Res. 248, 744-757. doi:10.1016/j.ejor.2015.07.017

Gong, X., De Pessemier, T., Joseph, W., Martens, L., 2016. A generic method for energy-efficient and energy-cost-effective production at the unit process level. J. Clean. Prod. 113, 508-522. doi:10.1016/j.jclepro.2015.09.020

Guo, L., Wang, S., Kang, L., Cao, Y., 2015. Agent-based manufacturing service discovery method for cloud manufacturing. Int. J. Adv. Manuf. Technol. 81, 2167-2181. doi:10.1007/s00170-0157221-0

Gutowski, T., Dahmus, J., Thiriez, A., 2006. Electrical Energy Requirements for Manufacturing Processes. Energy 2, 623-628.

He, Y., Li, Y., Wu, T., Sutherland, J.W., 2015. An energy-responsive optimization method for machine tool selection and operation sequence in flexible machining job shops. J. Clean. Prod. 87, 245254. doi:10.1016/j.jclepro.2014.10.006

Ho, N.B., Tay, J.C., 2008. Solving multiple-objective flexible job shop problems by evolution and local search. IEEE Trans. Syst. Man Cybern. Part C Appl. Rev. 38, 674-685. doi:10.1109/TSMCC.2008.923888

Jia, S., Hu, Z.-H., 2014. Path-relinking Tabu search for the multi-objective flexible job shop scheduling problem. Comput. Oper. Res. 47, 11-26. doi:10.1016/j.cor.2014.01.010

Kacem, I., Hammadi, S., Borne, P., 2002. Pareto-optimality approach for flexible job-shop scheduling problems: Hybridization of evolutionary algorithms and fuzzy logic. Math. Comput. Simul. 60, 245-276. doi:10.1016/S0378-4754(02)00019-8

Kachitvichyanukul, V., Sitthitham, S., 2011. A two-stage genetic algorithm for multi-objective job shop scheduling problems. J. Intell. Manuf. doi:10.1007/s10845-009-0294-6

Kang, D., Lee, D.H., 2016. Energy and environment efficiency of industry and its productivity effect. J. Clean. Prod. 135, 184-193. doi:10.1016/j.jclepro.2016.06.042

Karthikeyan, S., Asokan, P., Nickolas, S., Page, T., 2012. Solving flexible job-shop scheduling problem using hybrid particle swarm optimisation algorithm and data mining. Int. J. Manuf. Technol. Manag. 26, 81. doi:10.1504/IJMTM.2012.051445

Krishnan, S.S., Sunder, P.S., Vunnam, V., Balasubramanian, N., 2013. Integrating low carbon and energy efficiency constraints in sustainable product design, in: CIRP Design 2012 - Sustainable Product Development. Springer-Verlag London Ltd, pp. 389-398. doi:10.1007/978-1-4471-4507$3 \_37$

Lei, D., 2008. A Pareto archive particle swarm optimization for multi-objective job shop scheduling. Comput. Ind. Eng. doi:10.1016/j.cie.2007.11.007

Lei, D., Zheng, Y., Guo, X., 2017. A shuffled frog-leaping algorithm for flexible job shop scheduling with the consideration of energy consumption. Int. J. Prod. Res. 55, 3126-3140. doi:10.1080/00207543.2016.1262082

Li, J., Pan, Q., Liang, Y.-C., 2010. An effective hybrid tabu search algorithm for multi-objective flexible job-shop scheduling problems. Comput. Ind. Eng. 59, 647-662. 
doi:10.1016/j.cie.2010.07.014

Li, J.-Q., Pan, Q.-K., Chen, J., 2012. A hybrid Pareto-based local search algorithm for multi-objective flexible job shop scheduling problems. Int. J. Prod. Res. 50, 1063-1078. doi:10.1080/00207543.2011.555427

Li, W., Zein, A., Kara, S., Herrmann, C., 2011. An investigation into fixed energy consumption of machine tools, in: Glocalized Solutions for Sustainability in Manufacturing - Proceedings of the 18th CIRP International Conference on Life Cycle Engineering. pp. 268-273. doi:10.1007/978-3642-19692-8-47

Liu, C.-H., Huang, D.-H., 2014. Reduction of power consumption and carbon footprints by applying multi-objective optimisation via genetic algorithms. Int. J. Prod. Res. 52, 337-352. doi:10.1080/00207543.2013.825740

Liu, Y., 2013. Sustainable competitive advantage in turbulent business environments. Int. J. Prod. Res. 51, 2821-2841. doi:10.1080/00207543.2012.720392

Liu, Y., Dong, H., Lohse, N., Petrovic, S., Gindy, N., 2014. An investigation into minimising total energy consumption and total weighted tardiness in job shops. J. Clean. Prod. 65, 87-96. doi:10.1016/j.jclepro.2013.07.060

Liu, Y., Liang, L., 2015. Evaluating and developing resource-based operations strategy for competitive advantage: an exploratory study of Finnish high-tech manufacturing industries. Int. J. Prod. Res. 53, 1019-1037. doi:10.1080/00207543.2014.932936

Lu, C., Gao, L., Li, X., Xiao, S., 2017. A hybrid multi-objective grey wolf optimizer for dynamic scheduling in a real-world welding industry. Eng. Appl. Artif. Intell. 57, 61-79. doi:10.1016/j.engappai.2016.10.013

Lu, M.S., Romanowski, R., 2013. Multicontextual dispatching rules for job shops with dynamic job arrival. Int. J. Adv. Manuf. Technol. 67, 19-33. doi:10.1007/s00170-013-4765-8

Mansouri, S.A., Aktas, E., Besikci, U., 2016. Green scheduling of a two-machine flowshop: Trade-off between makespan and energy consumption. Eur. J. Oper. Res. 248, 772-788. doi:10.1016/j.ejor.2015.08.064

Mastrolilli, M., Gambardella, L.M., 2000. Effective Neighbourhood Functions for the Flexible Job Shop Problem. J. Sched. 3, 3-20. doi:10.1002/(SICI)1099-1425(200001/02)3:1<3::AIDJOS32>3.0.CO;2-Y

May, G., Stahl, B., Taisch, M., Prabhu, V., 2015. Multi-objective genetic algorithm for energy-efficient job shop scheduling. Int. J. Prod. Res. 53, 7071-7089. doi:10.1080/00207543.2015.1005248

Mosheiov, G., Sarig, A., 2010. Minimum weighted number of tardy jobs on an m-machine flow-shop with a critical machine. Eur. J. Oper. Res. 201, 404-408. doi:10.1016/j.ejor.2009.03.018

Mouzon, G., Yildirim, M.B., 2008. A framework to minimise total energy consumption and total tardiness on a single machine. Int. J. Sustain. Eng. doi:10.1080/19397030802257236

Mouzon, G., Yildirim, M.B., Twomey, J., 2007. Operational methods for minimization of energy consumption of manufacturing equipment. Int. J. Prod. Res. 45, 4247-4271. doi:10.1080/00207540701450013

Ouelhadj, D., Petrovic, S., 2009. A survey of dynamic scheduling in manufacturing systems. J. Sched. doi:10.1007/s10951-008-0090-8

Pach, C., Berger, T., Sallez, Y., Bonte, T., Adam, E., Trentesaux, D., 2014. Reactive and energy-aware scheduling of flexible manufacturing systems using potential fields. Comput. Ind. 65, 434-448. doi:10.1016/j.compind.2013.11.008 
Qiu, X., Lau, H.Y.K., 2013. An AIS-based hybrid algorithm with PDRs for multi-objective dynamic online job shop scheduling problem. Appl. Soft Comput. J. doi:10.1016/j.asoc.2012.07.033

Qu, T., Yang, H.D., Huang, G.Q., Zhang, Y.F., Luo, H., Qin, W., 2012. A case of implementing RFIDbased real-time shop-floor material management for household electrical appliance manufacturers. J. Intell. Manuf. 23, 2343-2356. doi:10.1007/s10845-010-0476-2

Rabiee, M., Zandieh, M., Ramezani, P., 2012. Bi-objective partial flexible job shop scheduling problem: NSGA-II, NRGA, MOGA and PAES approaches. Int. J. Prod. Res. doi:10.1080/00207543.2011.648280

Rangsaritratsamee, R., Ferrell, W.G., Kurz, M.B., 2004. Dynamic rescheduling that simultaneously considers efficiency and stability. Comput. Ind. Eng. doi:10.1016/j.cie.2003.09.007

Shen, X.-N., Yao, X., 2015. Mathematical modeling and multi-objective evolutionary algorithms applied to dynamic flexible job shop scheduling problems. Inf. Sci. (Ny). 298, 198-224. doi:10.1016/j.ins.2014.11.036

Shivasankaran, N., Kumar, P.S., Raja, K.V., 2015. Hybrid Sorting Immune Simulated Annealing Algorithm For Flexible Job Shop Scheduling. Int. J. Comput. Intell. Syst. 8, 455-466. doi:10.1080/18756891.2015.1017383

Shrouf, F., Ordieres-Meré, J., García-Sánchez, A., Ortega-Mier, M., 2014. Optimizing the production scheduling of a single machine to minimize total energy consumption costs. J. Clean. Prod. 67, 197-207. doi:10.1016/j.jclepro.2013.12.024

Subaï, C., Baptiste, P., Niel, E., 2006. Scheduling issues for environmentally responsible manufacturing: The case of hoist scheduling in an electroplating line, in: International Journal of Production Economics. doi:10.1016/j.ijpe.2004.12.008

Tay, J.C., Ho, N.B., 2008. Evolving dispatching rules using genetic programming for solving multiobjective flexible job-shop problems. Comput. Ind. Eng. 54, 453-473. doi:10.1016/j.cie.2007.08.008

Tseng, M., Lim, M., Wu, K., Zhou, L., Bui, D., 2017. A novel approach for enhancing green supply chain management using converged interval-valued triangular fuzzy numbers-grey relation analysis. Resour. Conserv. doi:10.1016/j.resconrec.2017.01.007

Tseng, M.L., Lin, R.J., Lin, Y.H., Chen, R.H., Tan, K., 2014. Close-loop or open hierarchical structures in green supply chain management under uncertainty. Expert Syst. Appl. doi:10.1016/j.eswa.2013.10.062

Vahit Kaplanoğlu, 2016. An object-oriented approach for multi-objective flexible job-shop scheduling problem. Expert Syst. Appl. 45, 71-84. doi:10.1016/j.eswa.2015.09.050

Vieira, G.E., Herrmann, J.W., Lin, E., 2003. Rescheduling manufacturing systems: A framework of strategies, policies, and methods, in: Journal of Scheduling. pp. 39-62. doi:10.1023/A:1022235519958

Wang, S., Liu, M., 2015. Multi-objective optimization of parallel machine scheduling integrated with multi-resources preventive maintenance planning. J. Manuf. Syst. 37, 182-192. doi:10.1016/j.jmsy.2015.07.002

Wang, S., Lu, X., Li, X.X., Li, W.D., 2015. A systematic approach of process planning and scheduling optimization for sustainable machining. J. Clean. Prod. 87, 914-929. doi:10.1016/j.jclepro.2014.10.008

Wang, W., Zhang, Y.F., Yang, H., Xu, J., 2017. IoT-enabled real-time energy efficiency optimization method for energy-intensive manufacturing enterprises. Int. J. Comput. Integr. Manuf. Under 
revi, 1-18. doi:10.1080/0951192X.2017.1337929

Xia, W., Wu, Z., 2005. An effective hybrid optimization approach for multi-objective flexible job-shop scheduling problems. Comput. Ind. Eng. 48, 409-425. doi:10.1016/j.cie.2005.01.018

Xing, L.N., Chen, Y.W., Yang, K.W., 2009. An efficient search method for multi-objective flexible job shop scheduling problems. J. Intell. Manuf. doi:10.1007/s10845-008-0216-Z

$\mathrm{Xu}$, B., Lin, B., 2016. Reducing carbon dioxide emissions in China's manufacturing industry: A dynamic vector autoregression approach. J. Clean. Prod. 131, 594-606. doi:10.1016/j.jclepro.2016.04.129

Yang, X., Zeng, Z., Wang, R., Sun, X., 2016. Bi-objective flexible job-shop scheduling problem considering energy consumption under stochastic processing times. PLoS One 11, 1-13. doi:10.1371/journal.pone.0167427

Yao, S., Jiang, Z., Li, N., Zhang, H., Geng, N., 2011. A multi-objective dynamic scheduling approach using multiple attribute decision making in semiconductor manufacturing. Int. J. Prod. Econ. 130, 125-133. doi:10.1016/j.ijpe.2010.12.014

Zhang, G., Shao, X., Li, P., Gao, L., 2009. An effective hybrid particle swarm optimization algorithm for multi-objective flexible job-shop scheduling problem. Comput. Ind. Eng. 56, 1309-1318. doi:10.1016/j.cie.2008.07.021

Zhang, L., Gao, L., Li, X., 2013. A hybrid genetic algorithm and tabu search for a multi-objective dynamic job shop scheduling problem. Int. J. Prod. Res. doi:10.1080/00207543.2012.751509

Zhang, R., Chiong, R., 2016. Solving the energy-efficient job shop scheduling problem: A multiobjective genetic algorithm with enhanced local search for minimizing the total weighted tardiness and total energy consumption. J. Clean. Prod. 112, 3361-3375. doi:10.1016/j.jclepro.2015.09.097

Zhang, Y.., Zhang, G., Qu, T., Liu, Y., Ray Y. Zhong, 2017. Analytical target cascading for optimal configuration of cloud manufacturing services. J. Clean. Prod. 151 AISC, 330-343.

Zhang, Y., Huang, G.Q., Sun, S., Yang, T., 2014. Multi-agent based real-time production scheduling method for radio frequency identification enabled ubiquitous shopfloor environment. Comput. Ind. Eng. 76, 89-97. doi:10.1016/j.cie.2014.07.011

Zhang, Y., Ren, S., Liu, Y., Si, S., 2017a. A big data analytics architecture for cleaner manufacturing and maintenance processes of complex products. J. Clean. Prod. 142, 626-641. doi:http://dx.doi.org/10.1016/j.jclepro.2016.07.123

Zhang, Y., Wang, J., Liu, S., Qian, C., 2017b. Game Theory Based Real-Time Shop Floor Scheduling Strategy and Method for Cloud Manufacturing. Int. J. Intell. Syst. 32, 437-463. doi:10.1002/int.21868

Zhang, Y., Zhang, G., Wang, J., Sun, S., Si, S., Yang, T., 2015. Real-time information capturing and integration framework of the internet of manufacturing things. Int. J. Comput. Integr. Manuf. 28, 811-822. doi:10.1080/0951192X.2014.900874

Zhong, R.Y., Dai, Q.Y., Qu, T., Hu, G.J., Huang, G.Q., 2013. RFID-enabled real-time manufacturing execution system for mass-customization production. Robot. Comput. Integr. Manuf. 29, 283292. doi:10.1016/j.rcim.2012.08.001 